US Army Corps

of Engineers ${ }_{\circledast}$

Engineer Research and

Development Center

\title{
Army Installations of the Future Industry Day 2019
}

\section{Summary Report}

Lance R. Marrano, Anne P. Koster, Susan R. Wolters, Louis B.

Bartels, Imes Chu, Brian C. Clark, Tapan C. Patel, Eileen T.

Westervelt, Irene A. Andsager, and Sean M. Wallace

\section{Installations of the Future}

$\div$

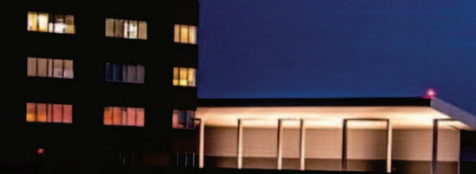

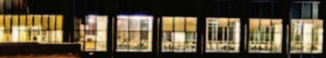

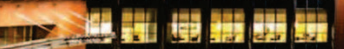

T IS n⿴囗十

$\operatorname{aim}=$

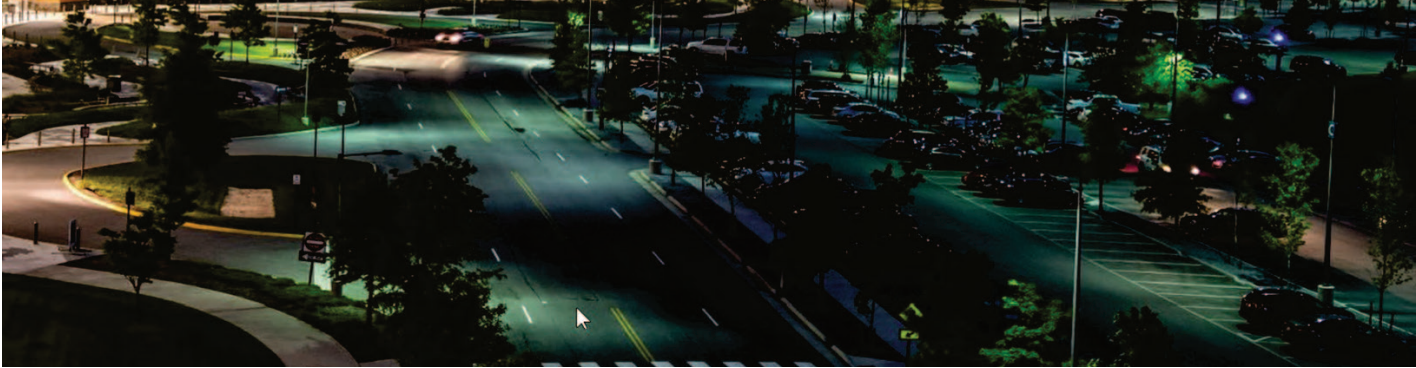


The U.S. Army Engineer Research and Development Center (ERDC) solves the nation's toughest engineering and environmental challenges. ERDC develops innovative solutions in civil and military engineering, geospatial sciences, water resources, and environmental sciences for the Army, the Department of Defense, civilian agencies, and our nation's public good. Find out more at www.erdc.usace.army.mil.

To search for other technical reports published by ERDC, visit the ERDC online library at https://erdclibrary.on.worldcat.org/discovery. 


\section{Army Installations of the Future Industry Day 2019}

\section{Summary Report}

Lance R. Marrano, Anne P. Koster, Louis B. Bartels, Imes Chu, Brian C. Clark, Tapan C.

Patel, Eileen T. Westervelt, Irene A. Andsager, and Sean M. Wallace

U.S. Army Engineer Research and Development Center (ERDC)

Construction Engineering Research Laboratory (CERL)

2902 Newmark Dr.

Champaign, IL 61824

Susan R. Wolters

U.S. Army Engineer Research and Development Center (ERDC)

Environmental Laboratory (EL)

3909 Halls Ferry Road

Vicksburg, MS 39180-6199

Final Technical Report (TR)

Approved for public release; distribution is unlimited.

Prepared for Assistant Secretary of the Army for Installations, Energy and Environment Washington, DC

Via: FAD 11256903m, “A1140-FY19 Industry Day.” 


\section{Abstract}

The Army Installations of the Future Industry Day was held on 23 May 2019 at the Renaissance Capital View hotel in Arlington, VA to identify the availability and maturity of specific commercial off-the-shelf (COTS) "smart installation" capabilities, technologies, and products; and to seek interest from industry in exploring potential approaches, requirements, standards, and/or specifications for pilot demonstrations at Army installations focused on 10 use-case technology areas. The Industry Day event included approximately 336 participants comprised of Academia (5), Industry (226), and Government (105). This report presents "road maps" that outline the Army's desired outcomes for the target technology areas and potential pilot technology demonstrations.

DISCLAIMER: The contents of this report are not to be used for advertising, publication, or promotional purposes. Citation of trade names does not constitute an official endorsement or approval of the use of such commercial products. All product names and trademarks cited are the property of their respective owners. The findings of this report are not to be construed as an official Department of the Army position unless so designated by other authorized documents. 


\section{Contents}
Abstract ii
Figures and Tables..
.. $\mathbf{v}$
Preface ...........................................................................................................................................
Executive Summary ............................................................................................................................

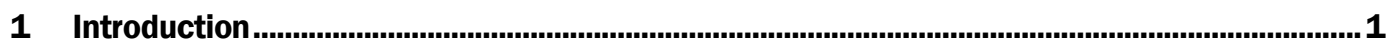

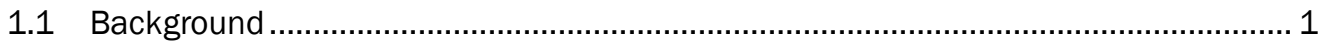

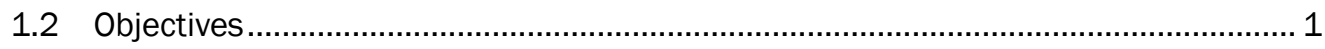

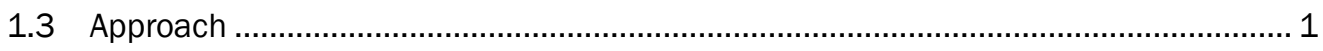

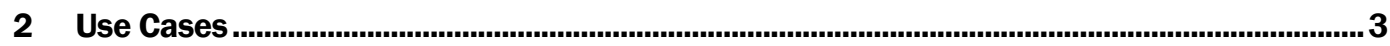

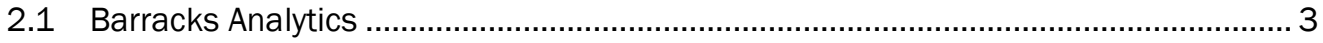

2.1.1 Technology description ....................................................................................... 3

2.1.2 Summary of technology capabilities, outcomes, and challenges................................... 3

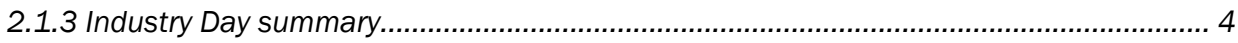

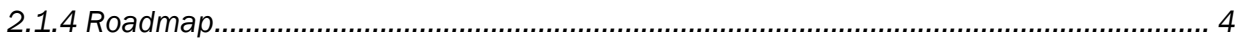

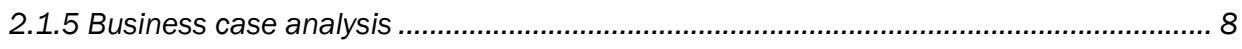

2.2 Integrated sensors (smart thermostats) ............................................................ 10

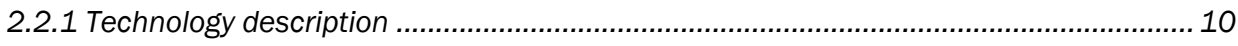

2.2.2 Summary of technology capabilities, outcomes, and challenges................................ 11

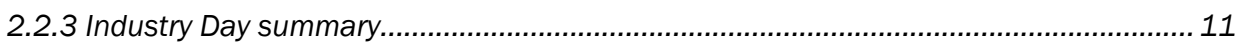

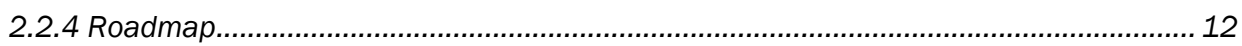

2.2.5 Business case analysis ......................................................................................... 14

2.3 Industrial Control System - Cyber Emergency Response Team (ICS-CERT) .............. 17

2.3.1 Technology description ............................................................................................ 17

2.3.2 Summary of technology capabilities, outcomes, and challenges.................................. 17

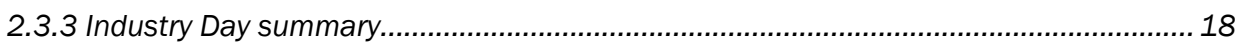

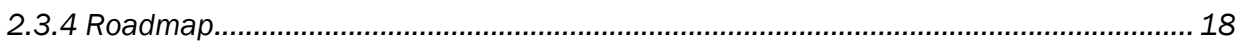

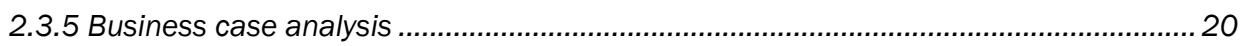

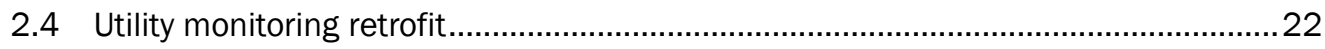

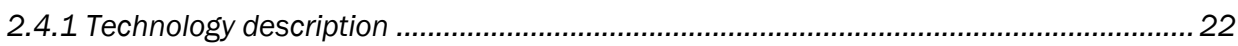

2.4.2 Summary of technology capabilities, outcomes, and challenges................................. 23

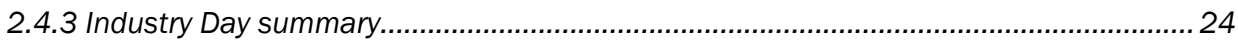

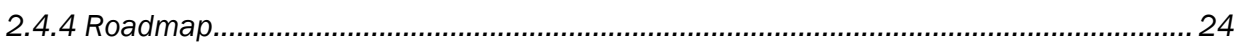

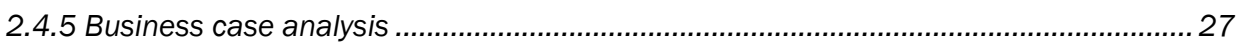

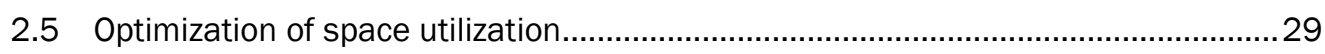

2.5.1 Technology description, the opportunity ...................................................................... 30

2.5.2 Summary of technology capabilities, outcomes, and challenges.................................. 30

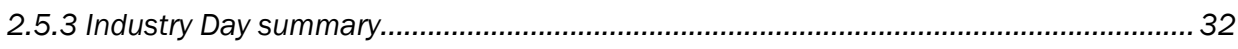

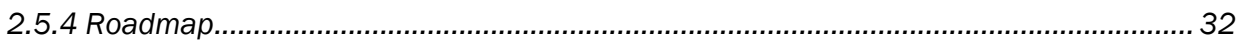

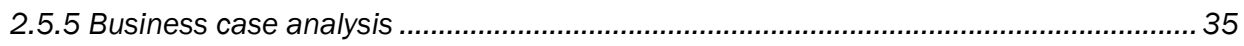




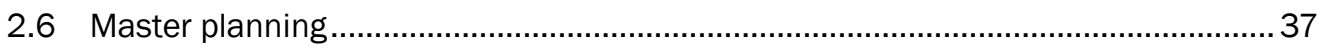

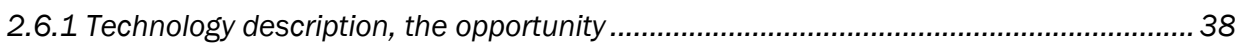

2.6.2 Summary of technology capabilities, outcomes, and challenges................................. 39

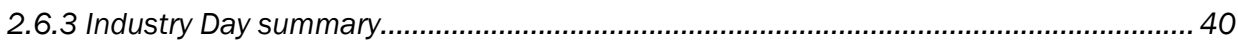

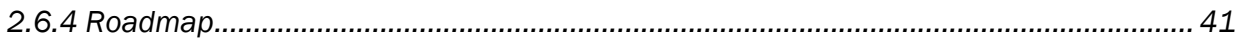

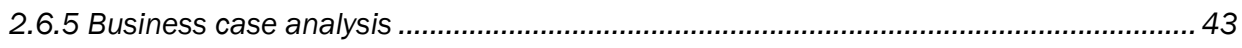

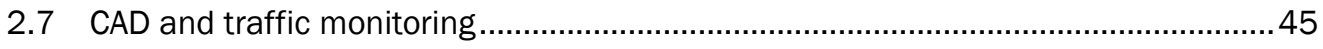

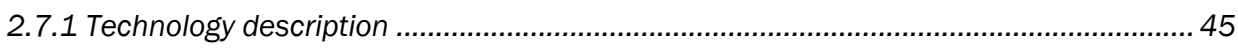

2.7.2 Summary of technology capabilities, outcomes, and challenges................................. 46

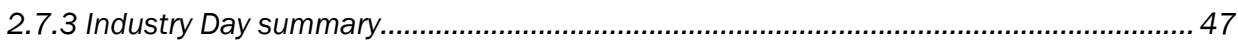

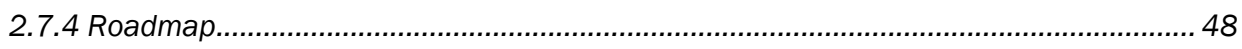

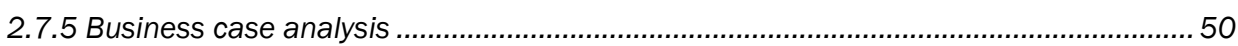

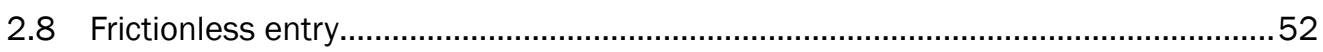

2.8.1 Technology description ............................................................................................. 52

2.8.2 Summary of technology capabilities, outcomes, and challenges................................ 53

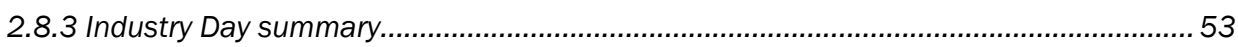

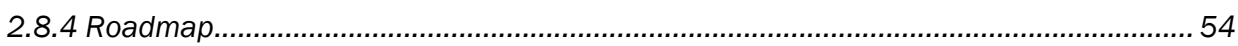

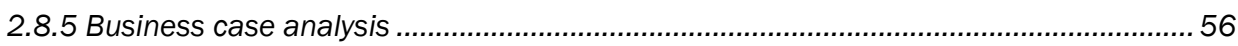

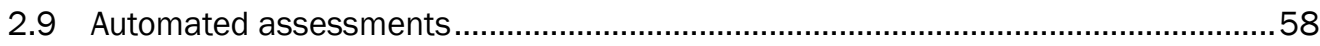

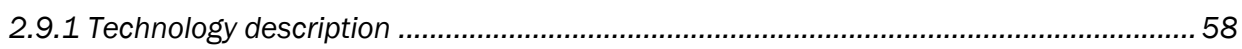

2.9.2 Summary of technology capabilities, outcomes, and challenges................................. 59

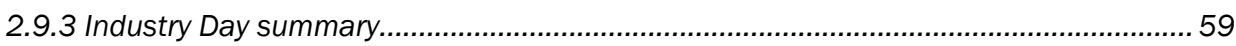

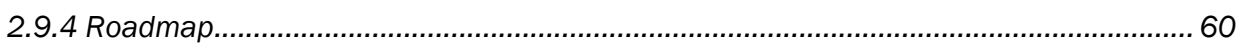

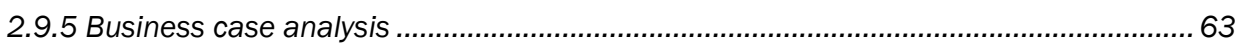

2.10 Child Development Center (CDC) Video Analytics ..................................................65

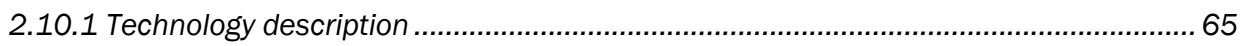

2.10.2 Summary of technology capabilities, outcomes, metrics, \& challenges......................6 66

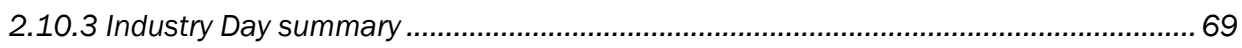

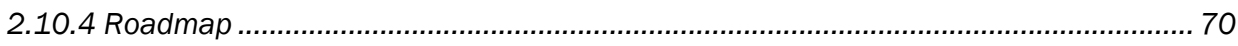

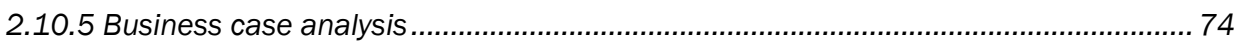

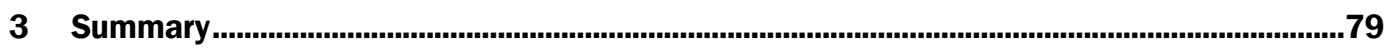

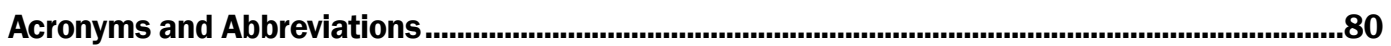

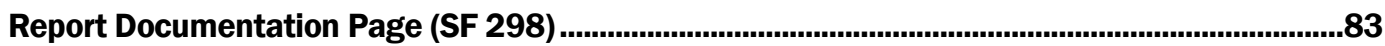




\section{Figures and Tables}

\section{Figures}

ES-1 Industry Day participants by affiliation ...................................................................... ix

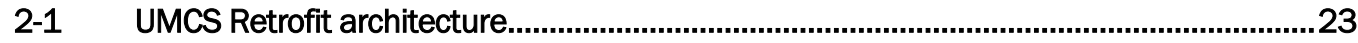

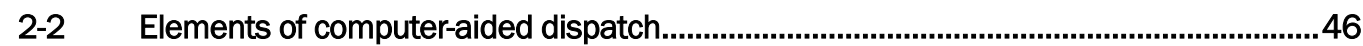

2-3 Demonstration of two Video Analytics software .........................................................59

2-4 Smart Child Development Center pilot program will take advantage of video surveillance and analytics technology capabilities...............................................66

\section{Tables}

ES-1 Army pilot roadmaps....................................................................................................... viii

2-1 Summary of Barracks Analytics retrofit technology capabilities,

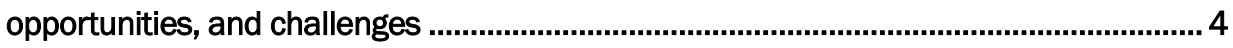

2-2 Barracks Analytics benefit breakdown ....................................................................10

2-3 Summary of integrated sensor capabilities, opportunities, and challenges...................11

2-4 Breakdown of anticipated qualitative benefits of the pilot technology.............................16

2-5 Summary of ICS-CERT technology capabilities, opportunities, and

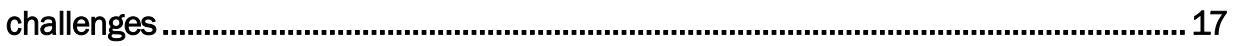

2-6 Breakdown of the anticipated quantifiable and non-quantifiable benefits

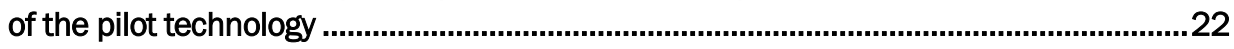

2-7 Summary of UMCS Retrofit technology capabilities, opportunities, and

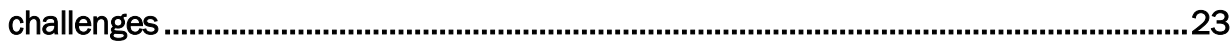

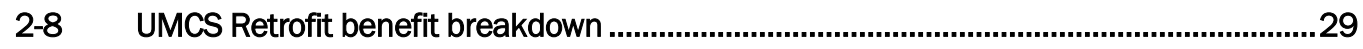

2-9 Summary of space utilization optimization technology ................................................31

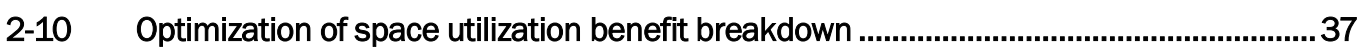

2-11 Summary of master planning and component plan technology.....................................39

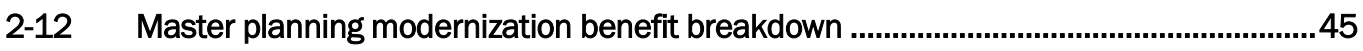

2-13 Summary of CAD \& Traffic Monitoring capabilities, opportunities, and challenges .................................................................................................................46

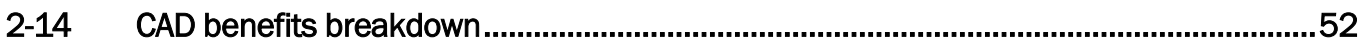

2-15 Summary of frictionless technology capabilities, opportunities, and

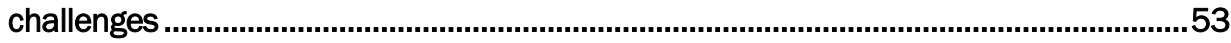

2-16 Frictionless entry quantifiable \& non-quantifiable benefits ......................................58

2-17 Summary of automated facility assessment technology capabilities,

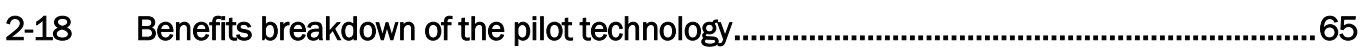

2-19 Summary of Smart CDC Video Analytics technology capabilities, opportunities, and challenges ......................................................................................67

2-20 Smart Child Development Center (CDC) benefits breakdown .........................................77 


\section{Preface}

This study was conducted for Office of the Assistant Secretary of the Army Installations Energy and the Environment (ASA[IE\&E]), via Funding Authorization Document (FAD) 11256903m, "WI A1140-FY19 Industry Day." The technical monitors were Dr. Jason R. Dorvee, Acting Associate Technical Director "Installations Forward," ERDC-CERL; and Mr. Lance Marrano, Director, Sustainment Management System Technical Center of Expertise, ERDC-CERL.

The work was facilitated by the Office of Technical Directors of the U.S. Army Engineer Research and Development Center, Construction Engineering Research Laboratory (ERDC-CERL). At the time of publication, the Acting Deputy Director of ERDC-CERL was Ms. Michelle Hanson and the Acting Director was Dr. Kumar Topudurti. The Deputy Director of Engineer Research and Development Center, Environmental Laboratory (ERDCEL) was Dr. Jack Davis and the Director was Dr. Edmond Russo.

COL Teresa A. Schlosser was Commander of ERDC, and Dr. David W. Pittman was the Director. 


\section{Executive Summary}

The Army held the first Installations of the Future industry day on 23 May 2019 at the Renaissance Capital View hotel in Arlington, VA, with more than 325 participants. Led by senior leadership from the Army's installation policy, strategy, execution, acquisition, and research organizations, this event signaled the Army's priorities in modernizing Army installations, with a focus on technology.

\section{Purpose}

The purpose of the Industry Day was to:

1. Identify the availability and applicability of COTS "smart installation" capabilities, technologies, and products for 10 specific technology use cases,

2. Seek industry participation to explore potential approaches, requirements, standards, and/or specifications for these use cases demonstrations at Army installations, and

3. Generate roadmaps which would ultimately lead to requests for proposals (RFPs) for specific technology focused pilot use-case demonstrations at Army installations.

\section{Approach}

This effort consisted of the following steps:

1. Market research of "smart city" use cases applicable to Army installations

2. Request for Information (RFI) to identify commercial "smart installation" capabilities for the generation of requirements and standards

3. Planning and execution of an Army Installations of the Future Industry Day

4. Post Industry Day analysis and development of pilot roadmaps.

\section{Market research}

Over 60 "smart" use cases were identified from existing Army and U.S. Department of Defense (DoD) DEMVAL technology proposals, installations' "Smart Bases" efforts, and presentations to ODASA(SI). These use cases were prioritized based upon expected return on investment (ROI) as well as technology maturity and availability, which resulted in selection of sixteen (16) pilots. These 16 pilots were aligned to installation functions of 
infrastructure, security, facility operations, and soldier/community to align with Army program managers and [commercial] solutions sought. Through existing partnerships, six were already underway to varying degrees. The remaining 10 were candidates for the Industry Day where industry could inform the Army of existing capabilities, standards, and requirements to help develop Army pilot roadmaps (Table ES-1).

Table ES-1. Army pilot roadmaps.

\begin{tabular}{|l|l|}
\hline Additional Pilots & Industry Day Pilots \\
\hline $\begin{array}{l}\text { 5G Infrastructure Utility Energy Service Contract } \\
\text { (UESC) Facilitation (Tennessee Valley Authority } \\
\text { [TVA], Redstone) }\end{array}$ & Barracks Analytics \\
\hline Perimeter Access Control (LSS) & Integrated Sensors for Facility Analytics \\
\hline Tactical Vehicle Micro Smart Grid (DTA) & $\begin{array}{l}\text { Industrial Control System - Cyber } \\
\text { Emergency Response Team (ICS-CERT) } \\
\text { Real-time Facility Control }\end{array}$ \\
\hline Building Fault Analytics (ICEE) for Army & Utility Monitoring \\
\hline Digital Twin (Georgia Tech) & Master Planning \\
\hline Autonomous Vehicle (US Ignite) & $\begin{array}{l}\text { Optimization of Space Utilization } \\
\text { Computer-Aided Dispatch (CAD) \& Traffic } \\
\text { Monitoring }\end{array}$ \\
\hline & Frictionless Entry \\
\hline & Automated Assessments \\
\hline & $\begin{array}{l}\text { Child Development Center (CDC) Video } \\
\text { Analytics }\end{array}$ \\
\hline
\end{tabular}

\section{Request for Information}

The U.S. Army Corps of Engineers (USACE) Engineer Research and Development Center (ERDC) issued an RFI for the 10 Industry Day pilots to solicit responses and gauge interest in participation. ERDC researchers evaluated over 70 companies' responses, matched the responses to the use cases (in some cases responses applied to more than one use case), and sent invitations to those companies. ERDC researchers further used the responses to shape panel questions and answers and ensuing discussion during the use-case breakout sessions.

\section{Industry Day}

A panel of leaders from the Army's installation policy, strategy, execution, acquisition, and research organizations kicked off the event and shared their perspectives, noting that their combined appearance signaled their shared priorities on Installations of the Future. Next, a cyber-expert panel 
addressed the criticality and emphasis of cyber concerns with deployment of "smart" technologies. Each technology in the 10 pilots has an Internet of Things (IoT) aspect and this session addressed questions and concerns common to all the pilots. The afternoon agenda consisted of five parallel tracks with two sessions each to explore the pilots more deeply with industry participants. In each session a panel of HQDA, IMCOM, ERDC, and cyber representatives delivered brief remarks and the remainder of the time was a dialogue between panel members and participants to understand the Army's requirements, how industry had existing solutions to meet those requirements, and how the Government needed to shape pilot procurements to address obstacles industry had encountered. Because multiple participants offered solutions for each pilot, additional discussion was devoted to determining open standards that could be used to create the ability for the Government to accept several vendors' solutions as part of enterprise-wide adoption should the pilot prove successful. Figure ES-1 shows the Industry Day participants by affiliation.

Figure ES-1. Industry Day participants by affiliation.

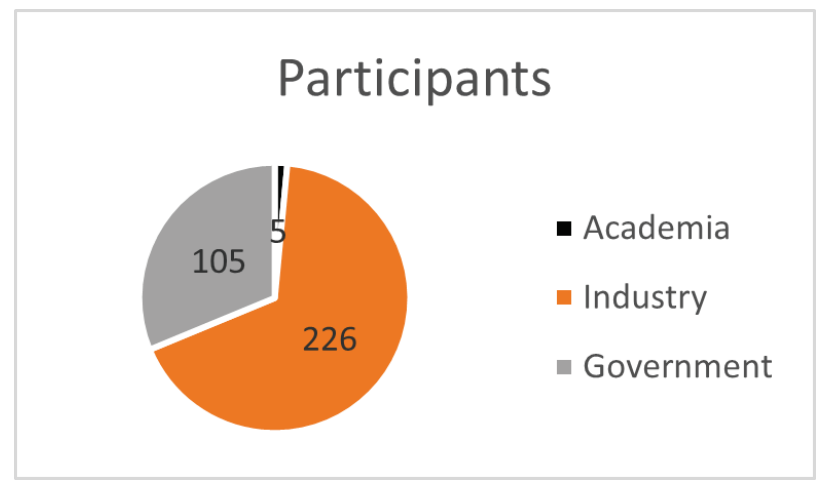

\section{Analysis and roadmaps}

ERDC moderators and recorders captured the discussions in each breakout session to create pilot roadmaps for each of the pilots. In addition to industry responses, analysis included pilot requirements, RFI responses, timetables, cost planning factors, and acquisition vehicles. Each of the 10 use cases is presented as a chapter in this report with a full presentation of these elements. 
THIS PAGE INTENTIONALLY LEFT BLANK 


\section{Introduction}

\subsection{Background}

The Army Installations of the Future Industry Day was held on 23 May 2019 at the Renaissance Capital View hotel in Arlington, VA.

The Industry Day event included approximately 336 participants comprised of Academia (5), Industry (226), and Government (105). Discussions with participants during Industry Day were recorded and later reviewed to develop roadmaps and paths forward towards individual use-case technology demonstrations at Army installations. Acquisition pathways were also identified to facilitate pilot use-case technology demonstrations.

This report summarizes the content of the Industry Day activities focusing on presenting "road maps" that outline the Army's desired outcomes for the target technology areas and potential pilot technology demonstration(s) (Chapter 2)

\subsection{Objectives}

The objectives of this effort were to:

1. Identify the availability and maturity of specific COTS "smart installation" capabilities, technologies, and products,

2. Seek interest from industry to participate in an Industry Day to explore potential approaches, requirements, standards, and/or specifications for 10 technology focused pilot use-case demonstrations at Army installations, and

3. Generate roadmaps that would ultimately lead to requests for proposals (RFPs) for specific technology focused pilot use-case demonstrations at Army installations.

\subsection{Approach}

This information-gathering effort involved a series of complex steps:

- Market research of "smart city" like technologies applicable to installations operations.

- Development of an RFI to identify existing industry "smart installation" capabilities for the generation of requirements and standards. 
- Evaluation of RFI responses.

- Planning and execution of an Army Installations of the Future Industry Day.

- Post Industry Day analysis.

- Development of roadmaps for technology focused pilot use cases at Army installations. 


\section{Use Cases}

\subsection{Barracks Analytics}

\subsubsection{Technology description}

Barracks Analytics will allow all levels of management to view trends, monitor and control building energy consumption, and detect equipment faults before they occur; saving maintenance and energy resources while increasing occupancy comfort levels. Managers and operators will monitor energy and maintenance trends, optimized facility energy consumption, utilize predictive maintenance to correct failures before they occur, and allow integrated analytics to perform continuous commissioning of facilities.

There are many aspects of this Barracks Analytics effort that are similar to or overlap with the Utility Monitoring Retrofit (Section 2.4) with its fault detection, maintenance analytics, and integration into installation-wide front-ends. This work is distinguished from that effort by its focus on barracks (which are largely represented on military installations and have unique operational issues and solutions); its integration with multiple existing data systems (metering, maintenance systems, real property accounting, and keyless entry systems) and its addition of occupancy sensing to analyze and optimize patterns of life within barracks. It may use the fault detection and equipment analytics developed from the Utility Monitoring Retrofit as part of its demonstrated capabilities.

\subsubsection{Summary of technology capabilities, outcomes, and challenges}

Based on a review of RFI responses from industry and Industry Day activities, Table 2-1 provides a summary of current installation facility-related capabilities, outcomes, and implementation or operational challenges associated with this technology. 
Table 2-1. Summary of Barracks Analytics retrofit technology capabilities, opportunities, and challenges.

\begin{tabular}{|c|c|c|}
\hline Capabilities & Outcomes & Challenges \\
\hline (What can it do?) & $\begin{array}{c}\text { (What are the } \\
\text { potential benefits?) }\end{array}$ & $\begin{array}{c}\text { (Implementation \& operational } \\
\text { challenges) }\end{array}$ \\
\hline $\begin{array}{l}\text { - Integration of building control } \\
\text { systems with maintenance } \\
\text { systems and real property } \\
\text { accounting to capture brick \& } \\
\text { mortar information into utility } \\
\text { dashboards } \\
\text { - Prioritized Operations and } \\
\text { Maintenance (O\&M) } \\
\text { recommendations with real- } \\
\text { time cost savings notifications } \\
\text { on O\&M, and cascading } \\
\text { component failure analysis } \\
\text { Occupancy monitoring to } \\
\text { establish maintenance } \\
\text { scheduling, space utilization, } \\
\text { and enable demand control } \\
\text { schemes }\end{array}$ & $\begin{array}{l}\text { - Comprehensive } \\
\text { understanding and } \\
\text { management of } \\
\text { assets } \\
\text { - Effective utilization } \\
\text { of limited } \\
\text { resources } \\
\text { - Strategic insights } \\
\text { on occupancy }\end{array}$ & $\begin{array}{l}\text { - } \text { Multi-vendor, multi-format } \\
\text { - Extenstems } \\
\text { and availability issues with } \\
\text { hardware, software and human } \\
\text { challenges } \\
\text { - Risk management framework } \\
\text { (RMF) cybersecurity } \\
\text { requirements } \\
\text { Multiple system owners } \\
\text { (Heating, Ventilating, and Air- } \\
\text { Conditioning [HVAC] } \\
\text { Operations, Real Property, } \\
\text { Acquisition) and users } \\
\text { (Administrators, Building } \\
\text { Managers, Equipment } \\
\text { Technicians) }\end{array}$ \\
\hline
\end{tabular}

\subsubsection{Industry Day summary}

\subsubsection{Use-case proponent}

- Fort Benning Garrison.

\subsubsection{Summary topics}

- Existing Building Stock: current features, occupancy patterns, inhouse ownership, and status of controls, metering, cybersecurity.

- Impacts: how integrated systems will support better understanding and management of the building stock, serve soldiers, and meet readiness goals.

- Barracks Analytics Retrofit Features: desirable features to include in a demonstration incorporating industry best practices.

\subsubsection{Roadmap}

\subsubsection{Planning}

- Establish Status and Vision: At targeted installation review, document the current platform(s) and status of existing data systems (HVAC controls, maintenance systems, real property management and acquisition systems), potential data collection solutions, and industry partners. With a diverse selection of system owners and stakeholders, 
collectively describe, refine, and prioritize desired capabilities for a combined data system and note anticipated benefits, expected challenges, and potential mitigation strategies.

- Capabilities: Focus on the following capabilities: integration of facility control systems with maintenance systems and real property accounting to capture brick \& mortar information into utility dashboards; prioritized O\&M recommendations with real-time cost savings notifications on O\&M and cascading component failure analysis; occupancy monitoring to establish maintenance scheduling, space utilization, and enable demand control.

- Research Partners: Invite industry to brainstorm on refinements to the vision, provide success stories from private industry, and recommend their potential role in bringing the vision to fruition. Some data may best be gathered by survey.

- Consider Solutions: Research and review data platforms for a potential barracks demonstration. Evaluate hardware or software solutions that could combine data streams into the installation's Utility Monitoring Control System front-end level to enable advanced analytics, visualization, and related features. Consider collaboration with the Utility Monitoring Retrofit demonstration to pull in fault detection and diagnostics of building equipment that is being established as part of that effort.

- Pilot Design \& Metrics: Develop a baseline pilot demonstration method to measure energy and non-energy impacts from Barracks Analytics retrofit implementation. It may include a before/after or sideby-side comparison of measures or surveyed metrics that are meaningful to project stakeholders. Determine if individual capabilities should be demonstrated separately or as a combination.

- Facility Considerations: To support energy data collection/analysis, buildings with interval energy metering are preferred; existing digital HVAC control systems and existing installation-wide Utility Monitoring and Control System (UMCS) are required to support retrofit approaches. For economy of scale cost-effectiveness, conduct pilots with facilities located on a single Army installation.

- Lifecycle Considerations: There are no special disposal costs (software and minor hardware only), however additional system monitoring, support, and licensing may be required as part of cybersecurity criteria and Barracks Analytics system sustainment. 
- Cybersecurity Considerations: RMF is required per Unified Facilities Criteria (UFC) 4-010-06 Cybersecurity of Facility-Related Control Systems.

- Project Team Considerations: ERDC-CERL Building Energy Systems and Microgrid Teams, ERDC-ITL Cybersecurity Team, UMCS Huntsville Mandatory Center of Expertise (MCX) Team (additional expertise may be required for central monitoring system user interface configuration, programming, contracting, and Army systems integration work [i.e., VTIME]) Real property, maintenance, acquisition offices, established industry subject matter experts (SMEs) on data integration.

\subsubsection{Milestones}

- Subtask 1: Research landscape of systems, buildings, stakeholders.

- Subtask 2: Establish vision of integrated system capabilities.

- Subtask 3: Collaborate with industry on desirable capabilities and potential solutions.

- Subtask 4: Develop site selection criteria for selecting existing buildings/systems as part of demonstrations: common HVAC configurations, existing/functioning control systems (inventory/assessment required), documentation available (mechanical/controls as-builts, RMF authorization artifacts, TAB if available), key installation support staff identified (EM, NEC, IAM/ISSO, DPW, HVAC Techs, etc.).

- Subtask 5: Develop solicitation with specifics for pilot technology demonstration and conduct request for proposals/quotations.

- Subtask 6: Develop Barracks Analytics retrofit contracting package to include scope of work and specific base bid and option tasks for specific facilities, functionalities, and deliverables associated with the pilot effort following site coordination using existing installation staff contacts and established stakeholder relationships.

- Subtask 7: Implement remedial repair following pilot contract award, perform detailed building-level assessments and data system assessments and to determine existing controls infrastructure improvements to ensure data integrity and availability necessary to provide Barracks Analytics retrofit functionality.

- Subtask 8: Provide installation, testing, training, quality assurance, and hand-off of new software and hardware required to enable Barracks Analytics retrofit capabilities (e.g., integrated data, prioritized O\&M tasks, occupancy monitoring). 
- Subtask 9: Perform data collection and analysis at prescribed schedules and in accordance with criteria provided to determine successful performance objectives including business case analysis.

- Subtask 10: Document results in final report/publications, facility criteria recommendations, lessons learned summaries, and next steps language.

\subsubsection{Acquisition recommendations}

- Contracting Vehicle Options: CERL OTA or BAA, USACE Huntsville UMCS MATOC, or local Mission Installation Contracting Command (MICC).

- Period of Performance: Approximately 24-36 months.

- 4 months of project development and acquisition.

- 9 months for RMF document generation concurrent with repairs.

- 12 months of data collection.

- 3 months for data analysis and final report with 2 months overlapping with data collection.

- Contracting Scope Recommended: recommend 2 initial facilities connected to a common installation UMCS front-end, with additional facilities added as funding is available.

\subsubsection{Stakeholder information}

- Coordination required from Huntsville Center, Alabama (HNC) UMCS and Cybersecurity MCXs as well as Land-Holding Command G-4 and G-6 offices.

- Installation: To be determined (TBD).

- Contract POC: TBD.

\subsubsection{Assumptions and other considerations}

- The Barracks Analytics retrofit use case was built around a Tridium JACE-gateway translator solution, the Business Case Analysis (BCA) below uses Niagara-related estimates, however this could be applied to the general case of a retrofit "box" at each building + front-end or cloud analytics + labor + RMF authorization.

- Installations largely contain existing UMCS configurations, however this retrofit approach is designed to augment the existing infrastructure to enable advanced action-oriented controls features for increases in overall facilities management effectiveness. 
- Revised controls criteria, dedicated contracting, and reachback/testing centers may be required for enterprise implementation.

\subsubsection{Business case analysis}

\subsubsection{Cost framework}

- Cost data to be collected will include initial hardware/software procurement, RMF cybersecurity authorization costs, costs for repairs/improvements identified, and annually recurring support/licensing costs.

- Savings data to be collected will include before-and-after building energy meter data and avoided equipment or labor cost data.

- Data analysis will include linear regression of energy data based on weather and occupancy normalization, energy modeling as needed to project savings scenarios, and life cycle cost analysis with annualized costs.

- Period of data collection will include approximately 1 year of monthly data collection beginning during implementation and completing 1 month after data collection completes.

\subsubsection{Alternatives}

- Status Quo: Status quos at installations on average are assumed to be a combination of building controls system front-ends with reactive diagnostics tools that include unformatted O\&M notifications, basic data trending, simple equipment scheduling/override, and floor-plan or system-level graphics. Utility metering is expected to be challenged in integrity and availability which will need repair to be useful. Systems are expected to be isolated from each other without easy ability to combine data streams for integrated analysis.

- Alternative Courses of Action (COAs): may include cloud (vs local server) configurations, $3^{\text {rd }}$ party vs native software applications, and additional analytics functionalities. Capabilities may be demonstrated as a combined suite of systems or as select combination.

- COA selection: will be based on competitive procurement and availability of funds for additional funding of contract options.

- Pilot technologies and COAs are expected to support the following:

- Alignment to mission: Facilitating cost-effective connection to legacy or otherwise isolated building controls systems can enable installation-level smart building capabilities to support Army lines of effort for Modernization, Readiness, Reform, and People. 
○ Support to personnel and community: Utility Monitoring Retrofit technologies can improve early detection and reduce downtown for facility-related issues that can enhance occupant comfort and quality of life for installation Service /members.

- Modernize infrastructure: The Multi-Doman Operations installation concept requires investment in network infrastructure to connect and more fully realize the benefits from building controls systems.

- Enable information sharing: while data from many building control systems (BCSs) has become available in the past decade, the integration of BCS data with other systems (O\&M, FDD, real property, acquisition) leads to actionable information and improved building operations. Barracks Analytics retrofit technologies will enable more standardized building integration and advanced interface features such as dashboard visualizations, fault detection notifications, and action-oriented O\&M recommendations.

- Energy reduction: based on synthesis studies on advanced facility data analytics demonstrations, a 9\% building-level energy reduction is targeted for Barracks Analytics retrofit efforts*. For a typical barracks with energy costs of $\$ 80 \mathrm{~K} / \mathrm{yr}$. this would be a $\$ 7.2 \mathrm{~K} / \mathrm{yr}$. savings. Extrapolated to the $\sim 8400$ barracks in the Army would lead to a savings of $\$ 60.5 \mathrm{M} / \mathrm{yr}$.

\subsubsection{Risk assessment \& mitigation strategies}

- Technical Risks: cybersecurity criteria for facility-related controls systems require project-tailored RMF costs, coordination, and system configuration that has the potential to delay demonstration efforts.

- Mitigation Strategy: engage the USACE Army Control System Cybersecurity Mandatory Center of Expertise (CSC-MCX) to lead RMF tailoring efforts and continuous monitoring processes.

- Cost Risks: Costs risks are low given that Barracks Analytics retrofit building and capability scope can be tailored to fit availability of funds, however there is uncertainty in specific levels of efforts required by industry to provide these capabilities.

- Mitigation Strategy: include contract options that best facilitate tailoring project award to availability of funding (e.g., 2 base bid facilities, 3 option task bids).

\footnotetext{
* Lawrence Berkeley National Laboratory. 2019. Synthesis of Year Three Outcomes in the Smart Energy Analytics Campaign
} 
- Business or Operational Risks: Utility Monitoring Retrofit-type benefits necessitate integration into existing installation O\&M workflow processes.

- Mitigation Strategy: include training and regularly scheduled O\&M progress meetings into the scope designed to foster maximum utilization of smart building capabilities enabled by Barracks Analytics retrofit technologies and investigate technical feasibility of data stream integration between Barracks Analytics retrofit and existing asset, financial, or workflow management systems.

- Adversary Risks: Increased networking of building controls may create additional cybersecurity vulnerabilities to be exploited by adversarial entities.

- Mitigation Strategy: comply with all UFC 4-010-06 Cybersecurity of Facility-Related Control Systems requirements and include RMF Maintenance and Support (M\&S) tasks during the duration of the pilot period of performance.

\subsubsection{Return on investment}

Table 2-2 lists the anticipated quantifiable and non-quantifiable benefits of the pilot technology.

Table 2-2. Barracks Analytics benefit breakdown.

\begin{tabular}{|c|l|}
\hline Anticipated Quantifiable Benefits & Anticipated Non-Quantifiable Benefits \\
\hline- & $\bullet$ Ensure building-level data integrity and availability \\
\hline- & $\begin{array}{l}\text { Compliance with UFC 4-010-06 Cybersecurity of } \\
\text { Facility-Related Control Systems }\end{array}$ \\
\hline $\begin{array}{l}\text { - } \begin{array}{l}\text { 9\%building-level energy reduction } \\
\text { relative to normalized baseline }\end{array} \\
\text { 15-year simple payback }\end{array}$ & $\begin{array}{l}\text { - Improved occupant comfort (e.g., Likert survey) } \\
\text { Improved O\&M effectiveness (e.g., Likert survey) } \\
\text { Improved understanding of building stock and } \\
\text { management options (such as under-utilized } \\
\text { spaces) }\end{array}$ \\
\hline
\end{tabular}

\subsection{Integrated sensors (smart thermostats)}

\subsubsection{Technology description}

Integrated sensors will enable DoD to achieve the goals of Executive Order 13834: Efficient Federal Operations to collect actionable data from facilities. Integrated sensors include various suites such as those that track $\mathrm{CO}_{2}$, temperature, occupancy, sound anomalies, and humidity networked through a control engine into an installation dashboard to collect analytics 
and enable efficient operations of the buildings. A pilot effort evaluating integrated sensors shall yield to determine the most cost-effective configuration of sensors for different facility categories will provide an enterprise solution for facility design standards and future integration projects.

\subsubsection{Summary of technology capabilities, outcomes, and challenges}

Based on a review of RFI responses from industry and Industry Day activities, Table 2-3 summarizes current installation facility-related capabilities, outcomes, and implementation or operational challenges associated with this technology.

Table 2-3. Summary of integrated sensor capabilities, opportunities, and challenges.

\begin{tabular}{|c|c|c|}
\hline Capabilities & Outcomes & Challenges \\
\hline (What can it do?) & $\begin{array}{c}\text { (What are the } \\
\text { potential benefits?) }\end{array}$ & $\begin{array}{c}\text { (Implementation \& } \\
\text { operational challenges) }\end{array}$ \\
\hline $\begin{array}{l}\text { - Improve decision-making by combining } \\
\text { various disparate sensors } \\
\text { - Predictive facility startup to save energy } \\
\text { - Reduce false alarms by combining fire } \\
\text { alarm sensors with } \mathrm{CO}_{2} \text { sensors } \\
\text { - Combine sound and vibration sensors on } \\
\text { pumps to determine if pumps/motors are } \\
\text { operating out of specifications }\end{array}$ & $\begin{array}{l}\text { Energy and } \\
\text { energy cost } \\
\text { reduction } \\
\text { - Enhanced O\&M } \\
\text { - } \text { Reduced false } \\
\text { fire alarms }\end{array}$ & $\begin{array}{l}\text { - Integrating older } \\
\text { systems with newer } \\
\text { systems } \\
\text { - Existing data integrity } \\
\text { and availability issues } \\
\text { - RMF cybersecurity } \\
\text { requirements }\end{array}$ \\
\hline
\end{tabular}

\subsubsection{Industry Day summary}

\subsubsection{1 use-case proponent}

- Fort Benning Garrison.

\subsubsection{Summary topics}

- Integrating old and newer sensors: How to best plan to integrate newer and older (20+ year) systems [together] in a cost-effective manner.

- Wireless sensors: To reduce cost, how can wireless sensors be used to deploy large numbers of sensors in a cost-effective manner while meeting cybersecurity requirements.

- Using existing data: In many cases, the Army is already collecting large amounts of data from existing systems. There are efficiencies to be gained from combining and analyzing the existing data to make better decision (vs. installing new hardware/sensors).

- Cybersecurity Strategies: what cybersecurity strategies is DoD using to integrate sensors (if any) and what gaps need to be addressed. 


\subsubsection{Roadmap}

\subsubsection{Implementation criteria}

- Objective: Evaluate hardware or software solutions that can be retrofitted or installed to the building or installation to enhance decisionmaking or improve current capabilities.

- Capabilities: Improve decision-making by combining various disparate sensors; predictive facility startup to save energy; reduce false alarms by combining fire alarm sensors with $\mathrm{CO}_{2}$ sensors; combine sound and vibration sensors on pumps to determine if pumps/motors are operating out of specifications.

- Pilot Design \& Metrics: Conduct a baseline demonstration method to measure energy reduction, simple payback, and O\&M or occupant impacts from integrated sensor implementation.

- Facility Considerations: To support energy data collection/analysis, buildings with interval energy metering are preferred; existing digital HVAC control systems and existing UMCS is required to aggregate data from various sensors and to implement predictive facility startup. Large facilities $>25 \mathrm{KSF}$ are preferred to demonstrate energy savings in pump/motor sensor technologies. Logged/historic data for fire responses are preferred to compare past and future savings for combined $\mathrm{CO}_{2} /$ fire alarm technologies.

- Lifecycle Considerations: There are no special disposal costs (software and minor hardware only). However additional instrumentation, system monitoring, support, and licensing may be required as part of implementation and ongoing sustainment.

- Cybersecurity Considerations: RMF is required per UFC 4-010-06 Cybersecurity of Facility-Related Control Systems.

- Project Team Considerations: ERDC-CERL Building Energy Systems Team, ERDC-ITL Cybersecurity Team, (additional expertise may be required for central monitoring system user interface configuration, programming, contracting, and Army systems integration work [i.e., VTIME]).

\subsubsection{Milestones}

- Subtask 1: Development of criteria for selecting existing buildings/systems as part of demonstrations: common HVAC configurations, existing/functioning control systems (inventory/assessment required), documentation available (mechanical/controls/fire system as- 
builts, RMF authorization artifacts), key installation support staff identified (EM, NEC, IAM/ISSO, DPW, HVAC Techs, etc.).

- Subtask 2: Development of contracting packages(s) to include scope of work and specific base bid and option tasks for specific facilities, functionalities, and deliverables associated with the pilot effort following site coordination using existing installation staff contacts and established stakeholder relationships.

- Subtask 3: Following pilot contract award, perform detailed buildinglevel assessments and to determine existing controls infrastructure improvements to ensure data integrity and availability necessary to provide fire system, motor/pump and control system upgrades.

- Subtask 4: Provide installation with testing, training, quality assurance, and new software and hardware/sensors required to enable integrated sensor technologies described above.

- Subtask 5: Perform data collection and analysis at prescribed schedules and in accordance with criteria provided to determine successful performance objectives including BCA.

- Subtask 6: Package results into final report/publications, facility criteria recommendations, lessons learned summaries, and next steps language.

\subsubsection{Acquisition recommendations}

- Contracting Vehicle Options: CERL BAA, USACE Huntsville UMCS MATOC, or local MICC.

- Period of Performance: Approximately 28 months.

- 4 months of project development and contract award, and RMF document generation.

- 3 months for installation/retrofit of selected facilities.

- 3 additional months before RMF authority to operate (ATO) is granted (10 months is conservative).

- 12 months of data collection to span multiple seasons.

- 6 months for data analysis and final report.

- Contracting Scope Recommended: recommend 20 facilities to ensure enough sensors/data can be collected to determine if the approach is cost effective for 1) Predictive facility startup, 2) False fire alarm detection and 3) Pump issue detection through combined sound/vibration sensors. Facilities within 5-10 years of construction would be ideal candidates for retrofit. 


\subsubsection{Stakeholder information}

- Coordination required from HNC UMCS and Cybersecurity MCXs as well as Land-Holding Command G-4 and G-6 offices.

- Installation: TBD.

- Contract POC: TBD.

\subsubsection{Assumptions and other considerations}

- Combine $\mathrm{CO}_{2}$, temp, humidity for predictive facility startup (save energy).

- The predictive facility startup is likely best for large buildings which can have significantly varying thermal loads depending on the season.

- Assumed total building space of approximately 100,000 sq $\mathrm{ft}$. This also assumes they have a front-end capable of supporting something like this (e.g. Tridium Niagara), this project would likely only require measurement and verification $(\mathrm{M} \& \mathrm{~V})$ to verify savings. Estimate 1.5 years for thorough analysis and to include enough seasonal variations.

- Combine $\mathrm{CO}_{2}$ sensors in HVAC systems with fire alarm to determine if there are any false fire alarms.

- This project likely requires a lot of buildings (estimated 10) since it cannot be guaranteed that one particular building will provide a false alarm.

- Combine sound/vibration sensors on pumps to determine if motors are starting to deviate from specifications or sense other issues such as misalignment.

\subsubsection{Business case analysis}

\subsubsection{Cost framework}

- Cost data to be collected will include initial hardware/software procurement, RMF cybersecurity authorization costs, costs for improvements identified, and annually recurring support/licensing costs.

- Savings data to be collected will include before-and-after building energy meter data and avoided equipment or labor cost data.

- Data analysis will include linear regression of energy data based on weather and occupancy normalization, energy modeling as needed to project savings scenarios, and life cycle cost analysis with annualized costs. 
- The projected timeline for this project is 31 months.

\subsubsection{Alternatives}

- Status Quo: Status quos at installations on average are assumed to be:

- React to all fire alarms as true positives with little ability to identify false positive alarms.

- Very minimal to no predictive startup, even with facilities with functioning building automation systems.

- Very minimal to no sounds/vibration sensors on pumps/motors. Other data sources may be used to identify issues such as pressure, flow rate, etc., but likely only happen on a limited base.

- Alternative Courses of Action (COAs): May include developing new algorithms based on existing limited sensor/data input, where available.

- COA selection: Will be based on competitive procurement and availability of funds for additional funding of contract options.

- Pilot technologies and COAs are expected to support the following:

- Alignment to mission: facilitating cost-effective connection to legacy or otherwise isolated building controls systems to collect actionable data and to support Army lines of effort for Modernization, Readiness, Reform, and People.

- Support to personnel and community: The proposed technologies can improve early detection of faults in motors/pump, reduce time, cost and resources associated with false fire alarms and reduce energy consumption and can enhance occupant comfort and quality of life for installation civilians and Service members.

- Modernize infrastructure: the multi-domain ops (MDO) Installation concept requires investment in network infrastructure to connect and more fully realize the benefits from building controls systems.

- Enable information sharing: while data from many BCSs has become available in the past decade, the information to be extracted from these buildings remains largely hidden. Installing and utilizing integrated sensor technologies will increase the amount of data on facilities and improved decision-making.

○ Energy and cost reduction: All proposed projects will enable cost and energy reductions. 


\subsubsection{Risk assessment \& mitigation strategies}

- Technical Risks: Cybersecurity criteria for facility-related controls systems require project-tailored RMF costs, coordination, and system configuration that has the potential to delay demonstration efforts.

- Mitigation Strategy: Engage the USACE Army Control System Cybersecurity Mandatory Center of Expertise (CSC-MCX) to lead RMF tailoring efforts and continuous monitoring processes.

- Cost Risks: Costs risks are low given that scope of the projects can be tailored to fit availability of funds, however there is uncertainty in specific levels of efforts required by industry to provide these capabilities.

- Mitigation Strategy: Include contract options that best facilitate tailoring project award to availability of funding (e.g., 12 base bid facilities, 4 option task bids).

- Business or Operational Risks: The proposed projects, if successful will need to integrate into existing installation O\&M workflow processes.

○ Mitigation Strategy: Include training and regularly scheduled O\&M progress meetings into the scope designed to foster maximum utilization of integrated sensors. Investigate technical feasibility of data stream integration between existing asset, financial, and workflow management systems.

- Adversary Risks: Increased networking of building controls may create additional cybersecurity vulnerabilities to be capitalized on by adversarial entities.

- Mitigation Strategy: Comply with all UFC 4-010-06 Cybersecurity of Facility-Related Control Systems requirements and include RMF $M \& S$ tasks during the duration of the pilot period of performance.

\subsubsection{Return on investment}

Table 2-4 lists the anticipated qualitative benefits of the pilot technology.

Table 2-4. Breakdown of anticipated qualitative benefits of the pilot technology.

\begin{tabular}{|l|}
\hline Anticipated Non-Quantifiable Benefits \\
\hline - Reduce energy consumption and energy cost \\
\hline - Improve occupant comfort \\
- Reduced cost and logistics from responding to false positives \\
\hline - Compliance with UFC 4-010-06 Cybersecurity of Facility-Related Control Systems \\
- Reduce lifecycle costs through improved O\&M \\
\hline
\end{tabular}




\subsection{Industrial Control System - Cyber Emergency Response Team (ICS-CERT)}

\subsubsection{Technology description}

This pilot is focused on cybersecurity solutions for securing, testing, and monitoring integrated informational technology/operational technology (IT/OT) systems. This includes securing multiple disparate interconnected systems, automated tools, enabling technologies, security devices, and solutions for the secure use of wireless technologies.

\subsubsection{Summary of technology capabilities, outcomes, and challenges}

Based on a review of RFI responses from industry and Industry Day activities, Table 2-5 summarizes current ICS-CERT related capabilities, outcomes, and implementation or operational challenges associated with this technology.

Table 2-5. Summary of ICS-CERT technology capabilities, opportunities, and challenges.

\begin{tabular}{|c|c|c|}
\hline Capabilities & Outcomes & Challenges \\
\hline (What can it do?) & (What are the potential benefits?) & $\begin{array}{c}\text { (Implementation \& operational } \\
\text { challenges) }\end{array}$ \\
\hline 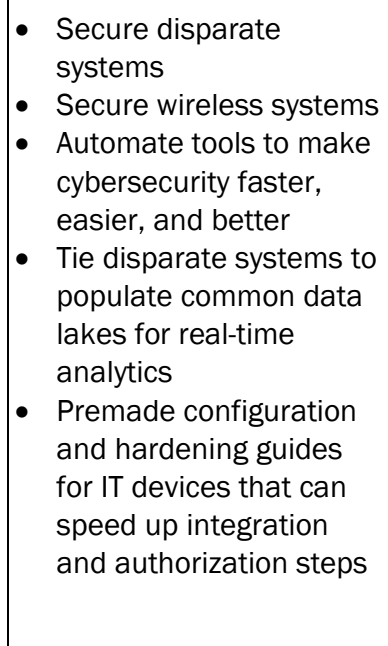 & $\begin{array}{l}\text { - Avoid use of base network } \\
\text { connections to control system } \\
\text { networks. Demonstrating such a } \\
\text { solution would give an OT network } \\
\text { equivalent to cellular (like 4G) } \\
\text { running on an Installation. } \\
\text { - Allow interconnection with other } \\
\text { cellular systems that can perform } \\
\text { analytics, etc. } \\
\text { - Using an overarching } \\
\text { RMF/agreement for 4G/5G/LTE } \\
\text { services could reduce the required } \\
\text { work for individual systems. }\end{array}$ & $\begin{array}{l}\text { - Variations in system } \\
\text { architecture require specific } \\
\text { testing at each installation } \\
\text { deployment } \\
\text { - } \text { Due to the evolving } \\
\text { cybersecurity threat, and the } \\
\text { associated lag in policy } \\
\text { documents, it can be difficult } \\
\text { for industry to prepare or } \\
\text { sufficiently support } \\
\text { - Lack of data sharing } \\
\text { standards for most control } \\
\text { systems, so the data may not } \\
\text { be available to share with } \\
\text { other systems } \\
\text { - Lack of data formatting } \\
\text { standards }\end{array}$ \\
\hline
\end{tabular}




\subsubsection{Industry Day summary}

\subsubsection{Use-case proponent}

- Fort Benning Garrison.

\subsubsection{Summary topics}

- Securing disparate systems: HVAC and CCTV in barracks, people tracking, data storage and real-time analytics, etc.

- Automated tools or enabling features: How to make cybersecurity for these systems faster, easier, and better.

- Use of wireless systems: How to manage the risk of LTE, $4 \mathrm{G}$, and 5 G solutions.

- RMF Challenges: What is RMF, how industry can prepare their systems for the RMF process, how the process evolves, how reciprocity can be leveraged, and how government standards like National Institute of Standards and Technology (NIST) are used?

- Cloud solutions: Scalability is a challenge, U.S. Federal Risk and Authorization Management Program (FedRAMP) is not RMF but it is required to be a cloud service provider, industry should sequence FedRAMP with RMF so they do not duplicate work, there is no standardized data format across DoD.

\subsubsection{Roadmap}

\subsubsection{Implementation criteria}

- Objective: Allow operators to quickly identify system status and/or health to improve the speed of deployment and integration for new systems.

- Capabilities: The ability to integrate OT systems on a wireless (4G/5G) network where no Department of Defense Information Network (DODIN) infrastructure is currently available or readily usable by the OT systems due to cybersecurity or technical concerns.

- Pilot Design \& Metrics: Implement a secure 4G/5G/LTE network for an OT solution. Since this has not previously been done at a military installation, the metric of success is a functioning and secure wireless network.

- Installation Considerations: Cellular infrastructure (towers) are preexisting, OT devices exist and are concentrated to a cellular device (x:1, not 1:1), the cellular network is contactor owned and operated, cellular data connection from OT devices to the control system enclave, 25 endpoints. 
- Lifecycle Considerations: There are no special disposal costs (software and minor hardware only), however additional system monitoring, support, and licensing may be required as part of cybersecurity criteria.

- Cybersecurity Considerations: RMF is required per UFC 4-010-06 Cybersecurity of Facility-Related Control Systems.

- Project Team Considerations: ERDC-CERL Building Energy Systems and Microgrid Teams, ERDC-ITL Cybersecurity Team, (additional expertise may be required for central monitoring system user interface configuration, programming, contracting, and Army systems integration work [i.e., VTIME]).

\subsubsection{Milestones}

- Subtask 1: Site identification and inventory.

- Subtask 2: Contract statement of work (SOW) development, solicitation, review, and award.

- Subtask 3: Engineering and RMF tasks.

- Subtask 4: Installation, configuration, and testing of the system following device integration.

- Subtask 5: Perform data collection and analysis at prescribed schedules and in accordance with criteria provided to determine successful performance objectives including BCA.

- Subtask 6: Package results into final report/publications, lessons learned summaries, and next steps language.

\subsubsection{Acquisition recommendations}

- Contracting Vehicle Options: CERL BAA, Open announcement, HNC MATOCs.

- Period of Performance: Approximately 38 months.

- Contracting Scope Recommended: two RMF ATOs, one for cellular solution and one for the OT with a 12-month demonstration period.

\subsubsection{Stakeholder information}

- Installation: TBD.

- Contract POC: TBD.

\subsubsection{Assumptions and other considerations}

Assumptions and considerations were addressed in "Installation Considerations" above. 


\subsubsection{Business case analysis}

\subsubsection{Cost framework}

- Cost data to be collected will include baseline enclave implementation costs, wireless network implementation cost, contracted network management costs, baseline enclave management costs, IT/OT authorization costs, baseline trenching for wired network costs.

- Savings data to be collected will include annual costs of operating the enclave through a contractor vs annual costs of operating an enclave over the Government network.

- Data analysis will include life cycle cost analysis with annualized costs.

- Period of data collection will not materially impact analysis once subscription costs are understood.

\subsubsection{Alternatives}

- Status quo: Status quo at installations on average are assumed to be a combination of building controls systems front-ends with reactive diagnostics tools that include unformatted O\&M notifications, basic data trending, simple equipment scheduling/override, and floor-plan or system-level graphics. Business-as-usual RMF processes that can take a year or more for an ATO and require duplicate efforts at each installation deployment even for relatively low impact controls systems.

- Alternative Courses of Action (COAs): May include cloud (vs local server) configurations, $3^{\text {rd }}$ party vs (native Utility Monitoring Retrofit) software applications, and additional analytics functionalities.

- COA selection: Will be based on competitive procurement and availability of funds for additional funding of contract options.

- Pilot technologies and COAs are expected to support the following:

- Alignment to mission: Army Strategy Line of Effort 2 - Modernization includes requirements for more integrated and reliable Army networks. Facilitating cost-effective connection to legacy or otherwise isolated building controls systems can enable installation-level smart building capabilities to support Army lines of effort for Modernization, Readiness, Reform, and People.

- Support to personnel and community: A wireless network for facility-related controls systems that better enables user interfaces for Quality of Life improvements to living and working environments complements Army retention and modernization strategies. Utility Monitoring Retrofit technologies can improve early 
detection and reduce downtown for facility-related issues that can enhance occupant comfort and quality of life for installation civilians and Service members.

- Modernize infrastructure: The MDO installation concept requires investment in network infrastructure to connect and more fully realize the benefits from building controls systems.

- Enable information sharing: Securing wireless devices and integrating disparate Facility Related Control Systems (FRCS) networks directly enables information sharing for analytics and decision-making purposes or platforms while data from many BCSs has become available in the past decade, the information to be extracted from these buildings remains largely hidden. Utility Monitoring Retrofit technologies will enable more standardized building integration and advanced interface features such as dashboard visualizations, fault detection notifications, and action-oriented O\&M recommendations.

$\circ$ Energy reduction: N/A.

\subsubsection{Risk assessment \& mitigation strategies}

- Technical Risks: Cybersecurity criteria for facility-related controls systems require project-tailored RMF costs, coordination, and system configuration that has the potential to delay demonstration efforts.

- Mitigation Strategy: Engage the USACE Army Control System Cybersecurity Mandatory Center of Expertise (CSC-MCX) to lead RMF tailoring efforts and continuous monitoring processes.

- Cost Risks: Costs risks are moderate given novel approach for network solutions and analytics features.

- Mitigation Strategy: Establish a coordination team with CIO G6, ASA(IE\&E), DCS G-9, AMC/IMCOM, NETCOM, USACE HQ, USACE CSC-MCX, USACE ERDC-CERL/ITL, and/or others to regularly strategize on approaches and mitigation needs.

- Business or Operational Risks: Technology transfer of any network solution to the Army enterprise-level requires operational considerations including life cycle sustainment, policy development, cybersecurity monitoring phase activities, and contracting methods.

- Mitigation Strategy: Include a Technology Transfer package as part of this effort to articulate the needs associated with delivery of any related solutions to the Army enterprise. 
- Adversary Risks: Increased networking of building controls may create additional cybersecurity vulnerabilities to be capitalized on by adversarial entities.

- Mitigation Strategy: Comply with all UFC 4-010-06 Cybersecurity of Facility-Related Control Systems requirements and include RMF M\&S tasks during the duration of the pilot period of performance.

\subsubsection{Return on investment}

Table 2-6 lists the anticipated quantifiable and non-quantifiable benefits of the pilot technology.

Table 2-6. Breakdown of the anticipated quantifiable and non-quantifiable benefits of the pilot technology.

\begin{tabular}{|l|l|}
\hline Anticipated Quantifiable Benefits & Anticipated Non-Quantifiable Benefits \\
\hline $\begin{array}{l}\text { This overarching ATO will reduce the cost of } \\
\text { installing additional OT on the network }\end{array}$ & $\begin{array}{l}\text { Data connectivity between OT } \\
\text { systems }\end{array}$ \\
& $\begin{array}{l}\text { Demonstration of secure wireless } \\
\text { networks for the Army }\end{array}$ \\
\hline
\end{tabular}

\subsection{Utility monitoring retrofit}

\subsubsection{Technology description}

UMCS Retrofit will use COTS building-level upgrade solutions to enable software to alert in real-time any out of tolerance systems and anomalies in energy usage, target buildings for timely service (enhancing resilience), and use dashboard consolidation and simplification of information into immediate and actionable metrics for cost-effective operation (Figure 2-1). 
Figure 2-1. UMCS Retrofit architecture.

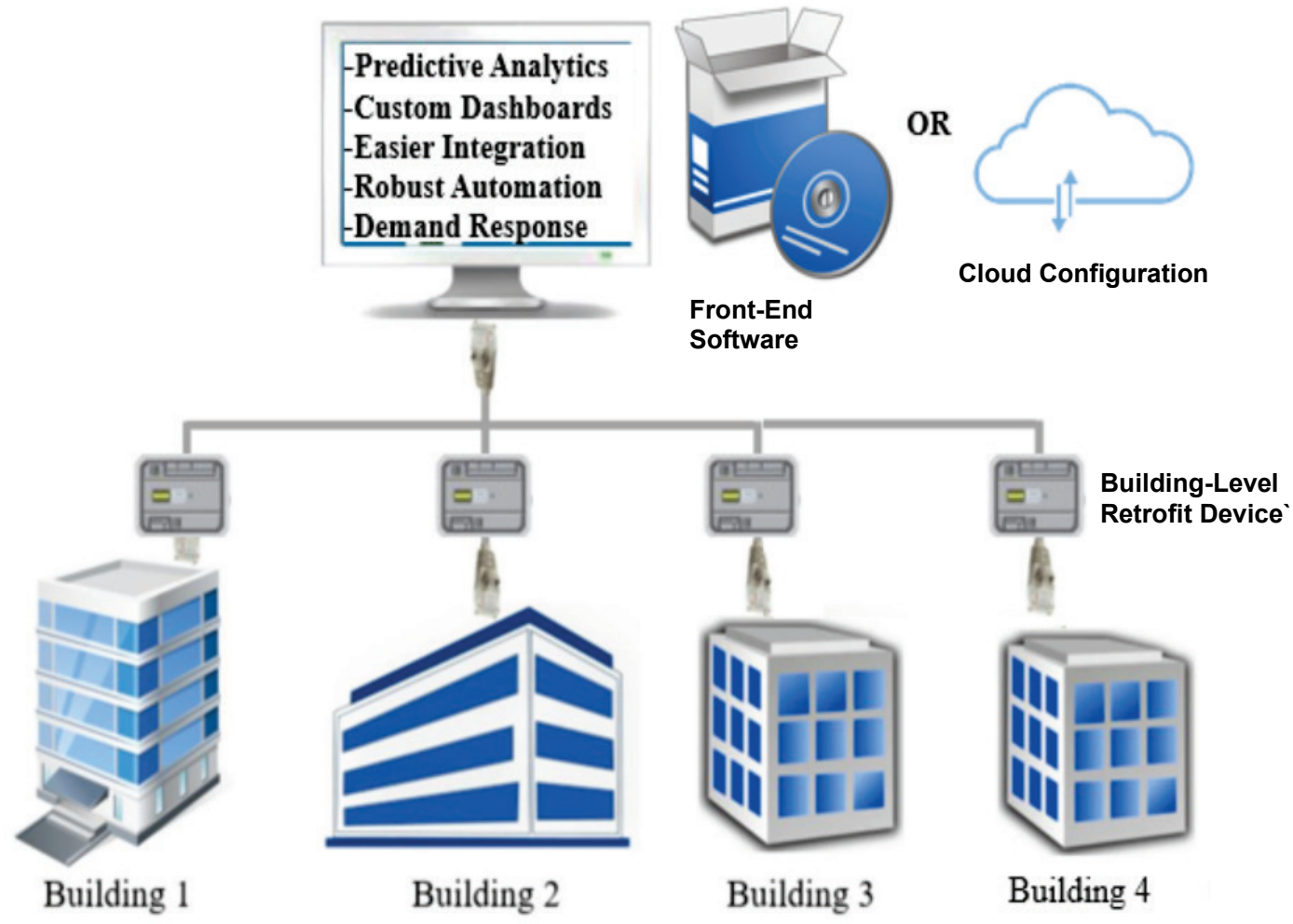

\subsubsection{Summary of technology capabilities, outcomes, and challenges}

Based on a review of RFI responses from industry and Industry Day activities, Table 2-7 summarizes current installation facility-related capabilities, outcomes, and implementation or operational challenges associated with this technology.

Table 2-7. Summary of UMCS Retrofit technology capabilities, opportunities, and challenges.

\begin{tabular}{|c|c|c|}
\hline Capabilities & Outcomes & Challenges \\
\hline (What can it do?) & $\begin{array}{c}\text { (What are the } \\
\text { potential benefits?) }\end{array}$ & $\begin{array}{c}\text { (Implementation \& } \\
\text { operational challenges) }\end{array}$ \\
\hline $\begin{array}{l}\text { - Automated fault detection/visualization to } \\
\text { package raw building data into actionable } \\
\text { information } \\
\text { - Demand/automated response for peak } \\
\text { utility shaving } \\
\text { - Robust integration of building controls } \\
\text { - } \text { systems to installation-wide front-ends } \\
\text { failing facilities equipment }\end{array}$ & $\begin{array}{l}\text { - Improved } \\
\text { installation } \\
\text { resilience } \\
\text { - Energy and } \\
\text { energy cost } \\
\text { reduction } \\
\text { - Enhanced O\&M }\end{array}$ & $\begin{array}{l}\text { - } \text { Multi-vendor building } \\
\text { controls } \\
\text { - } \text { Existing data integrity } \\
\text { and availability issues } \\
\text { - } \text { RMF cybersecurity } \\
\text { requirements }\end{array}$ \\
\hline
\end{tabular}




\subsubsection{Industry Day summary}

For the full details of this use case including participants, presentation content, and full discussions please see Section 4 Company Participation Appendices.

\subsubsection{Use-case proponent}

- Fort Benning Garrison.

\subsubsection{Summary topics}

- Leveraging Existing Controls Infrastructure: How to best improve the workability of the controls systems already in place at installations.

- Impacts: How to better use controls systems to improve building energy performance and maintenance programs.

- UMCS Retrofit Features: What are some of the most beneficial features included in typical commercial UMCS Retrofit scenarios?

- Implementation Challenges: What else needs to happen as part of a successful UMCS Retrofit implementation and what pitfalls can the Army avoid?

- Cybersecurity Strategies: What Retrofit configurations are commercially available that will help in cyber secure deployments of Utility Monitoring capabilities?

\subsubsection{Roadmap}

\subsubsection{Implementation criteria}

- Objective: Evaluate hardware or software solutions that can be easily retrofitted to the building or installation front-end level to enable advanced analytics, visualization, and related features.

\section{- Capabilities:}

- Software to alert, in real time, any out of tolerance systems and anomalies in energy usage, targeting buildings for timely service to enhance infrastructure resilience.

- Dashboard consolidation and simplification of information into immediate and actionable metrics for cost-effective operation.

- Pilot Design \& Metrics: Conduct a baseline intervention demonstration method to measure energy reduction, simple payback, and O\&M or occupant impacts from UMCS Retrofit implementation. 


\section{- Facility Considerations:}

- To support energy data collection/analysis, buildings with interval energy metering are preferred;

- Existing digital HVAC control systems and existing installationwide UMCS are required to support retrofit approaches, and facilities $>25 \mathrm{KSF}$ with variable occupancy levels or scheduling are preferred to best demonstrate energy reduction capabilities (e.g., barracks, instructional buildings, dining facilities, etc.).

- For economy of scale cost-effectiveness, conduct pilots with facilities located on a single Army installation.

- Lifecycle Considerations: There are no special disposal costs (software and minor hardware only), however additional system monitoring, support, and licensing may be required as part of cybersecurity criteria and UMCS Retrofit system sustainment.

- Cybersecurity Considerations: RMF is required per UFC 4-010-06 Cybersecurity of Facility-Related Control Systems.

- Project Team Considerations: ERDC-CERL Building Energy Systems and Microgrid Teams, ERDC-ITL Cybersecurity Team, UMCS MCX Team, (additional expertise may be required for central monitoring system user interface configuration, programming, contracting, and Army systems integration work [i.e., VTIME]).

\subsubsection{Milestones}

- Subtask 1: Development of criteria for selecting existing buildings/systems as part of demonstrations: common HVAC configurations, existing/functioning control systems (inventory/assessment required), documentation available (mechanical/controls as-builts, RMF authorization artifacts, TAB if available), key installation support staff identified (EM, NEC, IAM/ISSO, DPW, HVAC Techs, etc.).

- Subtask 2: Development of UMCS Retrofit contracting package to include scope of work and specific base bid and option tasks for specific facilities, functionalities, and deliverables associated with the pilot effort following site coordination using existing installation staff contacts and established stakeholder relationships.

- Subtask 3: Following pilot contract award, perform detailed buildinglevel assessments and to determine existing controls infrastructure improvements to ensure data integrity and availability necessary to provide UMCS Retrofit functionality.

- Subtask 4: Provide installation, testing, training, quality assurance, and hand-off of new software and minor hardware required to enable 
UMCS Retrofit capabilities (e.g., dashboard visualization, automated demand response sequences, predictive analytics, etc.).

- Subtask 5: Perform data collection and analysis at prescribed schedules and in accordance with criteria provided to determine successful performance objectives including BCA.

- Subtask 6: Package results into final report/publications, facility criteria recommendations, lessons learned summaries, and next steps language.

\subsubsection{Acquisition recommendations}

- Contracting Vehicle Options: USACE Huntsville UMCS MATOC or local MICC open procurement or 8(A) procurement.

- Period of Performance: Approximately 33 months.

○ 3 months of project development.

○ 12 months of RMF and contract development.

- 12 months of monthly data collection.

- 6 months of data analysis and report generation.

- Contracting Scope Recommended: recommend 12 initial facilities connected to a common installation UMCS front-end, with additional facilities and additional lower priority retrofit functionalities such as predictive analytics and integration with existing installation systems as separate contract options to test more advanced UMCS Retrofit features as desired.

\subsubsection{Stakeholder information}

- Coordination required from HNC UMCS and Cybersecurity MCXs as well as Land-Holding Command G-4 and G-6 offices.

- Installation: TBD.

- Contract POC: TBD.

\subsubsection{Assumptions and other considerations}

- The UMCS Retrofit use case was built around a Tridium JACE-type solution, the BCA below uses Niagara-related estimates, however this could be applied to the general case of a retrofit "box" at each building + front-end or cloud analytics + labor + RMF authorization.

- Installations largely contain existing UMCS configurations, however this retrofit approach is designed to augment the existing 
infrastructure to enable advanced action-oriented controls features for increases in overall facilities management effectiveness.

- Revised controls criteria, dedicated contracting, and reachback/testing centers may be required for enterprise implementation.

\subsubsection{Business case analysis}

\subsubsection{Cost framework}

- Cost data to be collected will include initial hardware/software procurement, RMF cybersecurity authorization costs, costs for repairs/improvements identified, and annually recurring support/licensing costs.

- Savings data to be collected will include before-and-after building energy meter data and avoided equipment or labor cost data.

- Data analysis will include linear regression of energy data based on weather and occupancy normalization, energy modeling as needed to project savings scenarios, and life cycle cost analysis with annualized costs.

- The projected time line for this project is 33 months.

\subsubsection{Alternatives}

- Status Quo: Status quos at installations on average are assumed to be a combination of building controls systems front-ends with reactive diagnostics tools that include unformatted O\&M notifications, basic data trending, simple equipment scheduling/override, and floor-plan or system-level graphics.

- Alternative Courses of Action (COAs): May include cloud (vs local server) configurations, $3^{\text {rd }}$ party vs (native UMCS Retrofit) software applications, and additional analytics functionalities.

- COA selection: Will be based on competitive procurement and availability of funds for additional funding of contract options.

- Pilot technologies and COAs are expected to support the following:

- Alignment to mission: Facilitating cost-effective connection to legacy or otherwise isolated building controls systems can enable installation-level smart building capabilities to support Army lines of effort for Modernization, Readiness, Reform, and People.

- Support to personnel and community: UMCS Retrofit technologies can improve early detection and reduce downtown for facility-related issues that can enhance occupant comfort and quality of life for installation civilians and Service members. 
- Modernize infrastructure: The MDO installation concept requires investment in network infrastructure to connect and more fully realize the benefits from building controls systems.

- Enable information sharing: While data from many BCSs has become available in the past decade, the information to be extracted from these buildings remains largely hidden. UMCS Retrofit technologies will enable more standardized building integration and advanced interface features such as dashboard visualizations, fault detection notifications, and action-oriented O\&M recommendations.

- Energy reduction: Based on synthesis studies on advanced facility data analytics demonstrations, a 9\% installation-level energy reduction is targeted for UMCS Retrofit efforts*.

\subsubsection{Risk assessment \& mitigation strategies}

- Technical Risks: Cybersecurity criteria for facility-related controls systems require project-tailored RMF costs, coordination, and system configuration that has the potential to delay demonstration efforts.

○ Mitigation Strategy: Engage the USACE Army Control System Cybersecurity Mandatory Center of Expertise (CSC-MCX) to lead RMF tailoring efforts and continuous monitoring processes.

- Cost Risks: Costs risks are low given that UMCS Retrofit building and capability scope can be tailored to fit availability of funds, however there is uncertainty in specific levels of efforts required by industry to provide these capabilities.

- Mitigation Strategy: Include contract options that best facilitate tailoring project award to availability of funding (e.g., 12 base bid facilities, 4 option task bids).

- Business or Operational Risks: UMCS Retrofit benefits necessitate integration into existing installation O\&M workflow processes.

- Mitisgation Strategy: Include training and regularly scheduled O\&M progress meetings into the scope designed to foster maximum utilization of smart building capabilities enabled by UMCS Retrofit technologies and investigate technical feasibility of data stream integration between UMCS Retrofit and existing asset, financial, or workflow management systems.

\footnotetext{
* Lawrence Berkeley National Laboratory. 2019. Synthesis of Year Three Outcomes in the Smart Energy Analytics Campaign
} 
- Adversary Risks: Increased networking of building controls may create additional cybersecurity vulnerabilities to be capitalized on by adversarial entities.

- Mitigation Strategy: Comply with all UFC 4-010-06 Cybersecurity of Facility-Related Control Systems requirements and include RMF M\&S tasks during the duration of the pilot period of performance.

\subsubsection{Return on investment}

Table 2-8 lists the anticipated quantifiable and non-quantifiable benefits of the pilot technology. (Army) Headquarters Installation Information System (HQIIS) and BUILDER real property data will be used for scaling purposes to perform BCA for Army-wide implementation.

Table 2-8. UMCS Retrofit benefit breakdown.

\begin{tabular}{|c|l|}
\hline \multicolumn{1}{|c|}{ Anticipated Quantifiable Benefits } & \multicolumn{1}{|c|}{ Anticipated Non-Quantifiable Benefits } \\
\hline- & $\begin{array}{l}\text { - Ensure building-level data integrity and } \\
\text { availability }\end{array}$ \\
\hline- & $\begin{array}{l}\text { Compliance with UFC 4-010-06 Cybersecurity } \\
\text { of Facility-Related Control Systems }\end{array}$ \\
\hline $\begin{array}{l}\text { 9\% installation-level energy reduction } \\
\text { relative to normalized baseline } \\
<10-y e a r \text { simple payback at the } \\
\text { installation-level }\end{array}$ & $\begin{array}{l}\text { - Improved occupant comfort (e.g., Likert } \\
\text { survey) }\end{array}$ \\
$\begin{array}{l}\text { Improved O\&M effectiveness (e.g., Likert } \\
\text { survey) }\end{array}$ \\
\hline
\end{tabular}

\subsection{Optimization of space utilization}

Planning for facility success means proactively managing a seemingly unending list of needs including responding to the national strategy for reducing the Federal Government's real estate footprint. Therefore, it is important to implement a space utilization and optimization plan that will identify beneficial changes to property and assets. Assets that may be moved or vacated to attain a more productive building portfolio should be considered to optimize building space utilization. To make space utilization changes, installations should consider cost savings, energy resilience and efficiency, and operational productivity prior to implementing their plans. 


\subsubsection{Technology description, the opportunity}

Effective space management relies on information about people, places, and processes. Industry is using readily available technology such as sensors and analytics for facility management and employee experience to reduce energy use.

Visualization. Technologies help installations to organize and spatially visualize where and in what type of space people work. The capability allows consumers to readily see relative size and proximity of buildings, rooms, and personnel for an entire base. For more detailed analysis, additional conventional map views and building layouts with room details are available. The user will be able to visualize current conditions and various proposed optimization solutions and manually adjust conditions through tools such as drag and drop.

Metrics and Constraints. Rather than defining the capability requirements based on decades-old and potentially unreliable historic resource requirements, current technology can provide "patters of life" data to inform updates to our requirements and standards supporting more efficient revisions to our out-of-date standards. This type of data, sometimes referred to as human analytics, can be used to better optimize space but also to analyze organizations to improve their overall performance. Since analysis and optimization would be ongoing, resources can be added, shared, or eliminated based on real utilization data moving forward.

Optimization Algorithms. The power of computer models is their ability to run limitless simulations to identify the most efficient and productive utilization, at a fraction of the time and cost than can be accomplished using manual methods.

\subsubsection{Summary of technology capabilities, outcomes, and challenges}

Based on a review of RFI responses from industry and Industry Day activities, Table 2-9 provides a summary of current installation space utilization-related optimization capabilities, outcomes, and implementation or operational challenges associated with this technology. This list is not comprehensive to those technologies supported by Industry participants during the Optimization in Space Utilization Session, but rather, generalizations based on technology types. 
Table 2-9. Summary of space utilization optimization technology.

\begin{tabular}{|c|c|c|}
\hline Capabilities & Outcomes & Challenges \\
\hline (What can it do?) & (What are the potential benefits?) & $\begin{array}{c}\text { (Implementation \& } \\
\text { operational challenges) }\end{array}$ \\
\hline $\begin{array}{l}\text { - Proprietary occupancy } \\
\text { sensors }\end{array}$ & $\begin{array}{l}\text { - Real-time and historical trends } \\
\text { for occupancy in individual and } \\
\text { collaborative spaces. }\end{array}$ & $\begin{array}{l}\text { - Data integrity } \\
\text { understudied }\end{array}$ \\
\hline $\begin{array}{l}\text { - IoT solutions, multiple } \\
\text { variations across } \\
\text { Industry }\end{array}$ & $\begin{array}{l}\text { - Activity monitoring, intelligent } \\
\text { spaces, and wayfinding, and } \\
\text { asset tracking. }\end{array}$ & $\begin{array}{l}\text { - Requires Wi-Fi and } \\
\text { Local Area Network } \\
\text { (LAN) networks, } \\
\text { technology requires } \\
\text { RMF }\end{array}$ \\
\hline $\begin{array}{l}\text { - } \text { IoT solutions + } \\
\text { ARCHIBUS }\end{array}$ & $\begin{array}{l}\text { Extracts data from BUILDER to } \\
\text { determine space utilization, } \\
\text { evaluate condition over time, } \\
\text { schedule actual move. }\end{array}$ & $\begin{array}{l}\text { - } \text { Requires } \mathrm{Wi-Fi} \text { and LAN } \\
\text { networks, technology } \\
\text { requires RMF }\end{array}$ \\
\hline $\begin{array}{l}\text { - Real-time Virtual Master } \\
\text { Planning (ReVAMP) } \\
\text { capability using digital } \\
\text { twins }\end{array}$ & $\begin{array}{l}\text { - Enhanced facility utilization and } \\
\text { allocation data. }\end{array}$ & $\begin{array}{l}\text { - Existing data integrity } \\
\text { and availability issues }\end{array}$ \\
\hline $\begin{array}{l}\text { Comprehensive, } \\
\text { integrated asset } \\
\text { management portfolio } \\
\text { capability }\end{array}$ & $\begin{array}{l}\text { - Optimization of Space } \\
\text { Utilization, integration of } \\
\text { planning data, and Data and } \\
\text { Information Integration, } \\
\text { Synchronization and } \\
\text { Discrepancy Resolution. }\end{array}$ & $\begin{array}{l}\text { - Patchwork development } \\
\text { would require rewrite }\end{array}$ \\
\hline $\begin{array}{l}\text { - Comprehensive planning } \\
\text { platform }\end{array}$ & $\begin{array}{l}\text { - Modernize the Army planning } \\
\text { work flow in a digital framework } \\
\text { to enable strategic and long- } \\
\text { term planning for installations in } \\
\text { support of Army missions and } \\
\text { customers. } \\
\text { - Asset visibility and } \\
\text { accountability. } \\
\text { - Alignment of Army strategic } \\
\text { objectives and operational plans } \\
\text { from the Army Command } \\
\text { (Acom), up through the } \\
\text { Secretariat, DoD, and Congress } \\
\text { with all installation- and district- } \\
\text { level planning activities from } \\
\text { with asset management and } \\
\text { component plans. } \\
\text { A common operation picture to } \\
\text { enable collaborative planning at } \\
\text { the installation level by } \\
\text { integrating planning processes } \\
\text { which support the installation } \\
\text { development process. } \\
\text { Make measurement and } \\
\text { verification of all decisions } \\
\text { measurable. }\end{array}$ & - Calibration to Army \\
\hline
\end{tabular}




\subsubsection{Industry Day summary}

\subsubsection{Use-case proponent}

- Fort Hunter Liggett.

\subsubsection{Summary topics}

- Leveraging Existing Sensor Infrastructure: How to best improve the workability of the space management including tracking and assignments already in place at installations (baseline) with a to-be capability leveraging existing technologies to extend space management a regional capability as well.

- Impacts: How to better use existing sensor infrastructure to improve building energy performance and maintenance programs.

- Optimization of Space Utilization Features: What are some of the most beneficial features included in typical commercial Space Utilization Optimization IoT applications and systems?

- Implementation Challenges: What else needs to happen as part of a successful Space Utilization Optimization implementation as a potential overlay or component of ePRISMS and VTIME and what pitfalls can the Army avoid?

- Cybersecurity Strategies: What configurations are commercially available that will help in cybersecure deployments of the capabilities?

\subsubsection{Roadmap}

\subsubsection{Implementation criteria}

- Objective: evaluate hardware or software solutions that can be easily retrofitted to the building or installation front-end level to enable advanced analytics, visualization, and related features.

- Capabilities: software to alert, in real time, any out of tolerance systems and anomalies in space utilization and requirements; dashboard consolidation and simplification of information into immediate and actionable metrics for cost-effective assignments and planning decision based on space utilization at both the installation, region, and installation.

\section{- Pilots Design \& Metrics:}

- Conduct a baseline intervention demonstration method to measure energy reduction, simple payback, and Sustainment, Restoration, and Modernization/Military Construction (SRM/MILCON) and tenant assignment impacts from Space Utilization Optimization 
implementation in development of Facility Utilization Studies and Stationing Packages.

- Conduct a baseline intervention demonstration method to measure SRM and MILCON avoidance compared against baseline (proscriptive requirements) to a to-be capabilities-based model based on real-time data and sensor driven information.

- Facility Considerations: For economy of scale cost-effectiveness, conduct pilots with facilities located on a single Army installation and 1-2 specific classes of buildings e.g. classrooms, administration, hangers, etc.

- Lifecycle Considerations: There are no special disposal costs (software and minor hardware only), however additional system monitoring, support, and licensing may be required as part of cybersecurity criteria and sensor sustainment.

- Cybersecurity Considerations: RMF is required per UFC 4-010-06 Cybersecurity of Facility-Related Control Systems.

- Project Team Considerations: ERDC-EL Applied Research Planning Support Center Team, ERDC-ITL Cybersecurity Team, (additional expertise may be required for central monitoring system user interface configuration, programming, contracting, and Army systems integration work [i.e., VTIME]).

\subsubsection{Milestones}

- Subtask 1: Development of scope of pilot including two alternative COAs. Select two installations within a region to develop a to-be capability for enterprise planning. The period of performance is estimated to be 18 months.

- Subtask 2: Development of criteria for selecting existing buildings/systems as part of demonstrations: admin, warehouses, barracks, etc., documentation available (Army Regulations on space requirements and Army stationing procedures, existing space management and decision support tools (CAMPS, ePRISMS, etc.), RMF authorization artifacts, TAB if available), key installation support staff identified (EM, NEC, IAM/ISSO, DPW, etc.).

- Subtask 3: Development of Optimization of Space Utilization contracting package to include scope of work and specific base bid and option tasks for specific facilities, functionalities, and deliverables associated with the pilot effort following site coordination using existing installation staff contacts and established stakeholder relationships.

- Subtask 4: Following pilot contract award, perform building (and potentially room)-level assessments and to determine existing sensor 
infrastructure modifications or new sensors or big-data sources to ensure data integrity and availability necessary to provide Space Utilization Optimization functionality.

- Subtask 5: Provide installation, testing, training, quality assurance, and hand-off of new software and minor hardware required to enable Space Utilization Optimization capabilities (e.g., dashboard visualization, automated and on-demand space decision impacts, regional feasibility stationing action planning decisions and impacts, predictive analytics, etc.).

- Subtask 6: Perform data collection and analysis at prescribed schedules and in accordance with criteria provided to determine successful performance objectives including BCA.

- Subtask 7: Package results into final report/publications, facility criteria recommendations, lessons learned summaries, and next steps language.

\subsubsection{Acquisition recommendations}

- Contracting Vehicle Options: EL ARPSC SATOC, GSA Schedule, or HNC Energy or Security MATOCs.

- Period of Performance: Approximately 18 months.

- 3 months of project development.

- 9 months of RMF and contract development.

- 3 months of data collection.

- 3 months of data analysis and report generation.

- Contracting Scope Recommended: recommend 12 initial facilities, with additional facilities, other installations for regional stationing capabilities, and additional lower priority space utilization optimization functionalities such as predictive analytics, capabilities-based model, and integration with existing installation systems as separate contract options to test more advanced Optimization and Space Utilization features as desired.

\subsubsection{Stakeholder information}

- Coordination required from Cybersecurity MCXs, G-9, and Land-Holding Command G-4 and G-6 offices.

- Installation: TBD.

- Contract POC: TBD. 


\subsubsection{Assumptions and other considerations}

- The Optimization and Space Utilization use case was built around a CAMPS or ePRISMS-type solution.

- Revised sensor criteria, dedicated contracting, and reachback/testing centers may be required for enterprise implementation.

\subsubsection{Business case analysis}

\subsubsection{Cost framework}

- Cost data to be collected will include initial hardware/software procurement, RMF cybersecurity authorization costs, and costs for repairs/improvements identified to sensors and software sustainment.

- Savings data to be collected will include:

○ before-and-after time to conduct space utilization studies/data.

○ time to make on-demand space assignments.

- time to make regional stationing decisions.

$\circ$ benefit to master planning and BUILDER data.

- modeled building energy data/savings.

- The projected time line for this project is 18 months.

\subsubsection{Alternatives}

- Status Quo: Space Utilization Studies for the Army portfolio require considerable human, time, and funding resources. Due to constant tenant moves, a space plan can quickly become outdated requiring manual updates to the plan and dissemination of that data. The challenge with operational requirements is the Army Command relies on proscriptive algorithmic requirements and tenants to tell planners what is right and what space is needed. Resulting plans often produce inflexible or duplicative space.

- Alternative Courses of Action (COAs): May include cloud (vs local server) configurations, $3^{\text {rd }}$ party software applications, additional analytics functionalities, installation and regional applications.

- COA selection: Will be based on competitive procurement and availability of funds for additional funding of contract options.

- Pilot technologies and COAs are expected to support the following:

- Alignment to mission: ensure mission requirements are validated and met and be able to more agilely address space and space assignments if the mission needs change.

- Support to personnel and community: Optimization of Space Utilization technologies can improve Quality of Life and Community 
Impact Analysis as space assignment and major stationing decisions impact Soldiers, Civilians, Families and local communities.

- Modernize infrastructure: The MDO installation concept requires investment in network infrastructure to connect and more fully realize the benefits from building sensors.

- Enable information sharing: While data from many real property systems has become available in the past decade, the information to be extracted from these systems remains largely isolated. Optimization of Space Utilization technologies will enable more standardized data integration and advanced interface features such as dashboard visualizations, issues with space requirements detection notifications, and action-oriented decision management recommendations.

- Energy reduction: Data space and energy reduction go hand in hand. It is anticipated that a direct energy savings and improved mission readiness can be measured in this pilot when applying flexible platforms, occupant consolidations, and simplifying redundant power delivery and demand reduction via employing Optimization of Space Utilization pilots.

\subsubsection{Risk assessment \& mitigation strategies}

- Technical Risks: Cybersecurity criteria for facility-related sensors and systems require project-tailored RMF costs, coordination, and system configuration that has the potential to delay demonstration efforts.

- Mitigation Strategy: Engage the USACE Army Control System Cybersecurity Mandatory Center of Expertise (CSC-MCX) to lead RMF tailoring efforts and continuous monitoring processes, as needed.

- Cost Risks: Costs risks are low given that Optimization of Space Utilization building and capability scope can be tailored to fit availability of funds, however there is uncertainty in specific levels of efforts required by industry to provide these capabilities.

- Mitigation Strategy: Include contract options that best facilitates tailoring project award to availability of funding (e.g., 12 base bid facilities, 4 option task bids).

- Mitigation Strategy: Other programs may benefit from integrated process schemes into the same facility sensors such as the active shooter programs, general building security, and occupant health and safety.

- Business or Operational Risks: Optimization of Space Utilization benefits necessitates integration into existing installation Master Planning and Army Stationing workflow processes. 
○ Mitigation Strategy: Include training into the scope designed to foster maximum utilization of smart building capabilities enabled by Optimization of Space Utilization technologies and investigate technical feasibility of data stream integration between this pilot and existing asset, financial, or workflow management systems.

- Adversary Risks: Increased networking of building sensors may create additional cybersecurity vulnerabilities to be capitalized on by adversarial entities.

○ Mitigation Strategy: Comply with all UFC 4-010-06 Cybersecurity of Facility-Related Control Systems requirements and include RMF M\&S tasks during the duration of the pilot period of performance.

\subsubsection{Return on investment}

Table 2-10 lists the anticipated quantifiable and non-quantifiable benefits of the pilot technology.

Table 2-10. Optimization of space utilization benefit breakdown.

\begin{tabular}{|c|l|}
\hline Anticipated Quantifiable Benefits & Anticipated Non-Quantifiable Benefits \\
\hline $\begin{array}{l}\text { On-demand, routine installation-scale utilization } \\
\text { assessments (compared to current 6-9 months } \\
\text { required for 1-2 facility categories in a Facilities } \\
\text { Utilization Study, from historical data) }\end{array}$ & $\bullet$ Ensure data integrity and availability \\
\hline $\begin{array}{l}\text { On-demand Stationing Packages (compared to } \\
\text { current x weeks/months, historical data to be } \\
\text { gathered) }\end{array}$ & $\bullet$ Ensure data integrity and availability \\
\hline- & $\bullet \begin{array}{l}50 \% \text { increase in satisfaction over } \\
\text { current process }\end{array}$ \\
\hline- & $\begin{array}{l}\text { 50\% improvement between pre- and } \\
\text { post- test indicating users have more } \\
\text { information to execute plan }\end{array}$ \\
\hline- & $\begin{array}{l}\text { Ease of integration of the technology } \\
\text { on the network }\end{array}$ \\
\hline- & $\begin{array}{l}\text { Compliance with UFC 4-010-06 } \\
\text { Cybersecurity of Facility-Related } \\
\text { Control Systems }\end{array}$ \\
\hline
\end{tabular}

\subsection{Master planning}

To successfully plan for the future growth, reduction, and sustainment of installations and ensure they meet mission, regulatory, and quality of life requirements, DoD established the requirement for installation master plans. To maintain their relevance as a useful planning and management tools, master plans and its components are required to be reviewed annually and updated as mission and installation requirements dictate, and 
thoroughly reviewed and updated at least every 5 years. Master Plan updates typically require outside installation support on average 6-12 months to develop. The average cost for the Army (Active Army, the Army National Guard/Army National Guard of the U.S., and the U.S. Army Reserve) is estimated to be $\$ 267 \mathrm{M}$ every 5 years for master plans.

Since data required to perform functions within real property master planning is vast, much of which are created by other functional areas and are challenging to access, a significant amount of time is devoted to collecting data. And although regulation prescribes a process with an objective for the development of consistency, often content and intent is considerably anecdotal. Once plans are created, access to planning decisions and outputs are not often available or understood well enough for reference elsewhere in the Planning, Programming, Budgeting, and Execution (PPBE) process or other functional business lines. Additionally, because the time and cost constraints of updating master plans are challenging, maintaining plans that reflect real-time changing mission requirements often render plans obsolete.

\subsubsection{Technology description, the opportunity}

Master Planning modernization objectives are to empower Army installation and strategic planners and decision makers by enabling better informed, relevant, and efficient real-time short and long-term investment decisions by developing, updating, and integrating future installation and component plans in an immersive experience of a digitized Army asset management and planning platform. To support this objective, a series of pilots are proposed for the following master planning processes and products as a master planning node to CERL's Virtual Testbed for Installation Mission Effectiveness (VTIME). Pilot 1 and 2 are priority pilots where Pilot 1 will consolidate installation-enterprise data views and asset portfolio management of all subsequent pilots, and Pilot 2 supports a required component of the Real Property Master Planning process. Pilot 3 is the next priority pilot as it is a required planning product and an overlay planning study to an installation's Area Development Plans (ADPs). All other pilots are listed in no particular order. Pilot summaries are as follows:

- Pilot 1. Army Planning Platform Common Operating Picture (APP COP).

- Pilot 2. Challenges ADP work flow digital transformation and discrete scenario generation and evaluation.

- Pilot 3. Installation Energy and Water Plan (IEWP) work flow digital transformation and discrete scenario generation and evaluation. 
- Pilot 4. Area Development Execution Plan (ADEP) work flow digital transformation.

- Pilot 5. Transportation Plan work flow digital transformation and discrete scenario generation and evaluation.

- Pilot 6. Space Optimization Plan work flow digital transformation and discrete scenario generation and evaluation.

- Pilot 7. Mobile Information Collection Application (MICA) customization, a faster, more efficient way for collecting and managing field data.

- Pilot 8. Investigation of real-time analytics applied to legacy data in plan-making activities from visioning, problem assessment, scenario planning, and plan implementation to redefine space requirements.

\subsubsection{Summary of technology capabilities, outcomes, and challenges}

Based on a review of RFI responses from industry and Industry Day activities, Table 2-11 provides a summary of current installation master planning modernization-related capabilities, outcomes, and implementation or operational challenges associated with this technology. This list is not comprehensive to those technologies supported by Industry participants during the Master Planning Session, but only those related to Master Planning are listed in Table 2-11.

Table 2-11. Summary of master planning and component plan technology.

\begin{tabular}{|c|c|c|}
\hline Capabilities & Outcomes & Challenges \\
\hline (what can it do?) & (What are the potential benefits?) & $\begin{array}{c}\text { (implementation \& } \\
\text { operational challenges) }\end{array}$ \\
\hline $\begin{array}{l}\text { - Traffic Management } \\
\text { use-case } \\
\text { - Advanced analytics for } \\
\text { sensor devise } \\
\text { management } \\
\text { - ReVAMP capability } \\
\text { using digital twins } \\
\text { - Development of new } \\
\text { metrics to meet } \\
\text { capability } \\
\text { requirements, and } \\
\text { Designs for } \\
\text { prototypical flexible } \\
\text { platforms } \\
\text { Comprehensive, } \\
\text { integrated asset } \\
\text { management portfolio } \\
\text { and planning platform } \\
\text { capability }\end{array}$ & $\begin{array}{l}\text { - Data integrating from diverse } \\
\text { real-time sensors for traffic } \\
\text { control and security } \\
\text { applications } \\
\text { - Energy and energy cost } \\
\text { reduction to inform } \\
\text { development of Army-required } \\
\text { Installation Energy and Water } \\
\text { Plans (IEWPs) } \\
\text { - Enhanced facility utilization and } \\
\text { allocation data } \\
\text { - Potential deviation from } \\
\text { outdated space requirements } \\
\text { supporting designs for } \\
\text { prototypical flexible platforms } \\
\text { - Optimization of Space } \\
\text { Utilization, integration of } \\
\text { planning data, and Data and } \\
\text { Information Integration, } \\
\text { Synchronization and } \\
\text { Discrepancy Resolution }\end{array}$ & $\begin{array}{l}\text { - } \text { Component Plans such as } \\
\text { Transportation Plans are } \\
\text { not pilot implementation } \\
\text { transfories to ADP digital } \\
\text { - Existing data integrity and } \\
\text { availability issues, and } \\
\text { Component Plans such as } \\
\text { Transportation Plans are } \\
\text { not pilot implementation } \\
\text { priorities to ADP digital } \\
\text { transformation } \\
\text { - Existing data integrity and } \\
\text { availability issues, and } \\
\text { Component Plans such as } \\
\text { Transportation Plans are } \\
\text { not pilot implementation } \\
\text { priorities to ADP digital } \\
\text { transformation } \\
\text { Under development }\end{array}$ \\
\hline
\end{tabular}




\begin{tabular}{|c|c|c|}
\hline Capabilities & Outcomes & Challenges \\
\hline (what can it do?) & (What are the potential benefits?) & $\begin{array}{c}\text { (implementation \& } \\
\text { operational challenges) }\end{array}$ \\
\hline & $\begin{array}{l}\text { - Modernize the Army planning } \\
\text { work flow in a digital framework } \\
\text { to enable strategic and long- } \\
\text { term planning for installations } \\
\text { in support of Army missions and } \\
\text { customers } \\
\text { - Asset visibility and } \\
\text { accountability } \\
\text { - Alignment of Army strategic } \\
\text { objectives and operational } \\
\text { plans from the ACOM, up } \\
\text { through the Secretariat, DoD, } \\
\text { and Congress with all } \\
\text { installation- and district-level } \\
\text { planning activities from with } \\
\text { asset management and } \\
\text { component plans } \\
\text { - A common operation picture to } \\
\text { enable collaborative planning at } \\
\text { the installation level by } \\
\text { integrating planning processes } \\
\text { which support the installation } \\
\text { development process } \\
\text { - Make measurement and } \\
\text { verification of all decisions } \\
\text { measurable }\end{array}$ & $\begin{array}{l}\text { - Patchwork development } \\
\text { would require rewrite } \\
\text { - Calibration to Army } \\
\text { Cultural paradigm shift will } \\
\text { be challenging for } \\
\text { enterprise adoption } \\
\end{array}$ \\
\hline
\end{tabular}

\subsubsection{Industry Day summary}

\subsubsection{Use-case proponent}

- G9.

- HQIMCOM.

- Installation TBD (candidates are those with completed master plans for ease of baseline development).

- HQUSACE.

\subsubsection{Summary topics}

- Leveraging Existing Installation and Real Property Data: How to best improve the workability and integration of HQIIS, Sustainment Management System (SMS) data, on post (geology, soils, topography, hydrology, vegetation, etc.) and off post (regional and vicinity conditions) planning data, RPLANS, GFEBS, etc. already in place at installations.

- Impacts: Develop a capability with data synchronization across disparate systems, feasibility of leveraging existing and new senor data sources, 
Effective utilization of limited resources and access of legacy databases, visualization of digitized master planning processes, time savings with COA generation and automation, and decision impacts to improve efficiency and effectiveness of master plan creation and sustainment.

- Installation and Enterprise: Communities for comprehensive understanding and management of assets for short- and long- range planning.

- Implementation Challenges: See Challenges in Summary of Technology Capabilities, Outcomes, and Challenges.

- Cybersecurity Strategies: See Implementation Challenges, first bullet.

\subsubsection{Roadmap}

\subsubsection{Implementation criteria}

- Objective: Evaluate available COTS and government off-the-shelf (GOTS) software solutions that can be easily calibrated for Army planning work flows.

- Capabilities: Software to enable an immersive web-based environment, leveraging data analytics (artificial intelligence [AI], machine learning, etc.) aligned with GIS (Army Installation Atlas), data forensics, Army legacy database interoperability, easy to use, dashboard consolidation and simplification with dynamic components for the purpose of creating and sustaining various master plans with better informed decision-making in a digital master planning platform compared to the baseline legacy master planning process without a digital master planning platform.

- Pilot Design \& Metrics: Conduct a baseline demonstration to include the reduced time required for master planning; the identified future alternatives, or courses of action (COAs) at a district and installation level; and the reduced time required to develop supporting master planning documentation. In addition to lower cost of analysis and master planning creation and sustainment, demonstration shall measure ease of use and increased understanding of planning outputs.

- Data Considerations: For economy of scale cost-effectiveness, conduct pilots for Army installations with recently development master plans to compare as-is and pilot (to-be) capabilities.

- Lifecycle Considerations: There are no special disposal costs (software and minor hardware only).

- Project Team Considerations: ERDC-EL Applied Research Planning Support Center (ARPSC), ERDC-CERL VTIME Teams, ERDC-ITL Cybersecurity Team, (additional expertise may be required). 


\subsubsection{Milestones}

- Subtask 1: Development of criteria for selecting installations and software as part of demonstrations: recently completed master planning products, easy to calibrate software to Army master planning process and system integration (VTIME), key installation and enterprise support staff identified dependent on the master planning modernization pilot (Master Planner, DPW Director, Energy Manager, Water Manager, NEC, DPTMS, etc.).

- Subtask 2: Development of Master Planning Modernization contracting package to include scope of work and ADP Digital Transformation base task and option tasks for other component plans digital transformation pilots.

- Subtask 3: During or following pilot contract award, host initial Army Planning Modernization Vision Plan Workshop to kick off to pilot to discuss pilot technology demonstrations and to capture Army Command vision of a system-of-systems to which these pilots would reside for Army access.

- Subtask 4: Following pilot contract award, develop an Army Planning Platform Common Operation Picture (APP COP) and master planning process necessary to provide required planning functionality.

- Subtask 5: Perform data collection and analysis in accordance with criteria provided to determine successful performance objectives including BCA.

- Subtask 6: Package results into final report/publications, Army regulation recommendations, lessons learned summaries, and next steps language.

\subsubsection{Acquisition recommendations}

- Contracting Vehicle Options: EL ARPSC SATOC or EL GSA Schedule.

- Period of Performance: Approximately 18 months.

○ 12 months for project development.

- 2 month of data collection.

- 4 months for data analysis and report generation.

- Contracting Scope Recommended: customization of existing software necessitated to calibrate to Army planning processes. 


\subsubsection{Stakeholder information}

- Coordination required DCS G9, HQIMCOM Master Planner, and select military installation Contract POC: TBD.

\subsubsection{Assumptions and other considerations}

- For these pilots, it will be assumed that the available data in other functional databases is in good condition.

- Use of an existing planning software is assumed to have minimum calibration needed to retrofit for Army planning purposes.

- Revised controls criteria, dedicated contracting, and reachback/testing centers may be required for enterprise implementation.

\subsubsection{Business case analysis}

\subsubsection{Cost framework}

- Cost data to be collected will include initial software procurement, if any, costs for software sustainment, and annually recurring support/licensing costs, if any.

- Savings data to be collected will include before-and-after time required to conduct master plan or component plan, depending on the pilot. This includes collecting data, verifying data, establishing a baseline and calibration, goal elicitation, analysis of alternatives, decision support, and reporting (master planning product).

- Time required will be measured in working days. Data will be collected on person-hours required as well. A typical planning study can take 612 months.

- Data analysis will include required time recorded in an electronic log over a time period from the start of the study at data collection through the time the study report is created. Comparison data from either a recently developed study or, if this data is not available, an average of five like studies will be used as the basis for the traditional master planning process. These records will be considered the baseline for comparison.

- The projected time line for this project is 18 months.

\subsubsection{Alternatives}

- Status Quo: Status quo (do nothing scenario) at installations on average is assumed to include 1-3 months data collection, varied analysis 
and outputs, no source or editable data that can be collocated with other functional databases.

- Alternative Courses of Action (COAs): May include various planning pilots e.g. Area Development Plans, Area Development Execution Plans, IEWPs, Sustainability Component Plans, Transportation Plans, Space Optimization Plans, etc.

- COA selection: Will be based on competitive procurement and availability of funds for additional funding of contract options.

- Pilot technologies and COAs are expected to support the following:

- Alignment to mission: Facilitating cost- and time-effective decisions to legacy or otherwise outdated decision support when installation missions or needs change rapidly by optimally supporting Army lines of effort for Modernization, Readiness, Reform, and People.

○ Support to personnel and community: Master Planning Modernization capabilities will allow installation leadership to make data-driven, real-time decision that understand the impacts to quality of life for installation civilians and Service members.

- Modernize infrastructure: The MDO installation concept requires investment in network infrastructure to connect and more fully realize the benefits from improved allied interoperability, AI, and autonomy.

- Enable information sharing: While data from master plans and component plans are meant to be available, they are largely done is in PDF or Word format where the information to be extracted from these studies remains largely hidden. Master Planning Modernization will enable data and decision support integration and advanced interface features such as dashboard visualizations and interoperability in other function datasets and databases.

- Energy reduction: With sustainable and energy-efficient development as a basic objective of a successful master plan, Federal energy mandates are anticipated to be more easily realized when standardization is targeted for Master Planning Modernization pilots.

\subsubsection{Risk assessment \& mitigation strategies}

- Technical Risks: Software calibration to Army planning requirements may require configuration that has the potential to delay demonstration efforts.

- Mitigation Strategy: Engage the Master Planning Modernization stakeholder team for minimum viable product (determined at Vision Workshop). 
- Business or Operational Risks: Master Planning Modernization benefits necessitate integration into existing PPBES workflow processes as well as the Installation Planning Board (IPB).

- Mitigation Strategy: Include training and regularly scheduled PPBES and IPB progress meetings into the scope designed to foster maximum utilization of system.

- Adversary Risks: While a compilation of unclassified information is normally not classified, the Defense Critical Infrastructure (DCI) notes that in certain circumstances information that would otherwise be marked UNCLASSIFIED may become classified when combined with other unclassified information.

- Mitigation Strategy: Comply with all Army Regulation (AR) 3805 and DCI Line of Effort (LOE) Security Classification Guide (SCG) guidance to remediate or mitigate vulnerabilities to aggregated data sensitivities.

\subsubsection{Return on investment}

Table 2-12 lists the anticipated quantifiable and non-quantifiable benefits of the technology.

Table 2-12. Master planning modernization benefit breakdown.

\begin{tabular}{|l|l|}
\hline \multicolumn{1}{|c|}{ Anticipated Quantifiable Benefits } & \multicolumn{1}{|c|}{ Anticipated Non-Quantifiable Benefits } \\
\hline $\begin{array}{l}10 \text { working days (compared to current 6-12 } \\
\text { months from historical data) time required } \\
\text { reduction to conduct planning study }\end{array}$ & Ensure data integrity and availability \\
\hline- & $\begin{array}{l}50 \% \text { increase in satisfaction over current } \\
\text { process }\end{array}$ \\
\hline- & $\begin{array}{l}50 \% \text { improvement between pre- and post- } \\
\text { test indicating users have more } \\
\text { information to execute plan }\end{array}$ \\
\hline $\begin{array}{l}\text { Ease of integration of the technology on the } \\
\text { network }\end{array}$ & \multicolumn{1}{|c}{-} \\
\hline
\end{tabular}

\subsection{CAD and traffic monitoring}

\subsubsection{Technology description}

Computer-Aided Dispatch (CAD) \& Traffic Monitoring provides an integrated intelligence and visualization platform for a single point of dispatch to coordinate multiagency operations during crisis and mass casualty situation. Consisting of a suite of software packages (see Figure 2-2) linked to various databases, this capability shall enhance the critical safety and welfare of an Army installation population enabling clear, rapid and effective 
deployment of emergency response. Solution will integrate multiple data sources, from open source traffic and travel time information to weather and evacuation routes, for comprehensive planning, efficient response, and effective coordination among multiple agencies.

Figure 2-2. Elements of computer-aided dispatch.

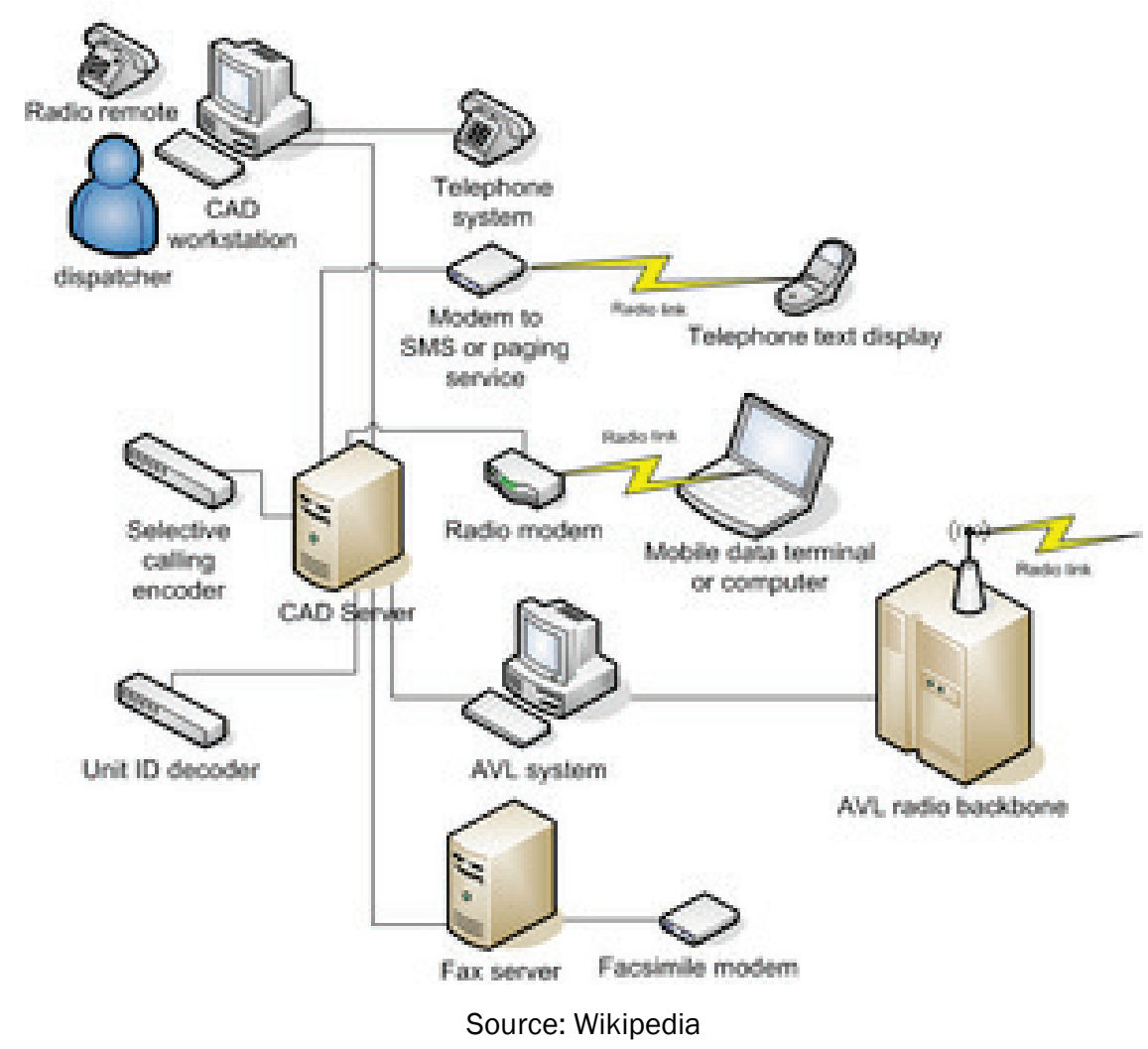

\subsubsection{Summary of technology capabilities, outcomes, and challenges}

Based on a review of RFI responses from industry and Industry Day activities, Table 2-13 provides a summary of current installation facility-related capabilities, outcomes, and implementation or operational challenges associated with this technology.

Table 2-13. Summary of CAD \& Traffic Monitoring capabilities, opportunities, and challenges.

\begin{tabular}{|c|c|c|}
\hline \multicolumn{1}{|c|}{ Capabilities } & \multicolumn{1}{c|}{ Outcomes } & \multicolumn{1}{c|}{ Challenges } \\
\hline (What can it do?) & $\begin{array}{c}\text { (What are the potential } \\
\text { benefits?) }\end{array}$ & $\begin{array}{c}\text { (Implementation \& operational } \\
\text { challenges) }\end{array}$ \\
\hline $\begin{array}{l}\text { - Provide Command } \\
\text { and Control during }\end{array}$ & $\begin{array}{l}\text { - Provide coordination among } \\
\text { multiagency responders } \\
\text { particularly in the areas of } \\
\text { ingress and egress during } \\
\text { response operations }\end{array}$ & $\begin{array}{l}\text { Data and information sharing will } \\
\text { be challenging from the local to } \\
\text { the national level. } \\
\text { Policy changes must be } \\
\text { implemented. }\end{array}$ \\
\hline
\end{tabular}




\begin{tabular}{|c|c|c|}
\hline Capabilities & Outcomes & Challenges \\
\hline (What can it do?) & $\begin{array}{c}\text { (What are the potential } \\
\text { benefits?) }\end{array}$ & $\begin{array}{c}\text { (Implementation \& operational } \\
\text { challenges) }\end{array}$ \\
\hline $\begin{array}{l}\text { - } \text { Dispatch } \\
\text { emergency } \\
\text { response within } \\
\text { one (1) minute of } \\
\text { receiving call } \\
\text { - } \text { Response must } \\
\text { reach within } 7 \\
\text { minutes to its } \\
\text { destination } \\
\text { - Commander must } \\
\text { have a Common } \\
\text { Operating Picture } \\
\text { (COP) }\end{array}$ & $\begin{array}{l}\text { - Save lives } \\
\text { - Decrease potential } \\
\text { escalation of disaster and } \\
\text { other cascading effects } \\
\text { - Enables a coordinated, } \\
\text { effective and efficient } \\
\text { response } \\
\text { - Establishes Command and } \\
\text { Control in the midst of } \\
\text { chaos }\end{array}$ & $\begin{array}{l}\text { - } \quad \text { Reed to look at entire ecosystem. } \\
\text { level; if it is too complicated, it will } \\
\text { not be used. } \\
\text { - } \text { Army currently has no standalone } \\
\text { system for emergency responder } \\
\text { network. } \\
\text { - } \text { Need to make decision and share } \\
\text { information at the point of } \\
\text { dispatching, but cyber security } \\
\text { regulations states that you cannot } \\
\text { bring data from outside the } \\
\text { network. } \\
\text { - Connectivity in the cantonment } \\
\text { areas is challenging. } \\
\text { - Hard to locate people inside } \\
\text { military installations after they } \\
\text { call 911 from a building. In a large } \\
\text { facility, it is hard to find which } \\
\text { floor the 911 caller is located. } \\
\text { - } \text { Multiagency response and } \\
\text { interagency coordination is } \\
\text { difficult in the Army network. } \\
\text { Ensuring compliance with cyber } \\
\text { security regulations while } \\
\text { achieving the Mission with } \\
\text { partners will be challenging. } \\
\text { (PII) is difficult among civilians. }\end{array}$ \\
\hline
\end{tabular}

\subsubsection{Industry Day summary}

\subsubsection{Use-case proponent}

- Fort Benning Director of Emergency Services.

- Program Executive Office for Intelligence, Electronic Warfare \& Sensors.

\subsubsection{Summary topics}

- Leveraging Existing Models: Explore using Fort Benning's model and modify appropriately in collaboration with stakeholders. Survey current CAD best practices.

- Holistic Solution: CAD is just the hub; solution must consider entire installation ecosystem.

- Information Sharing Challenges: Multiagency response and interagency coordination is extremely difficult in the Army network, 
particularly at the infrastructural, operational, connectivity, and organizational levels. For example, it is extremely difficult to bring outside data into the Army network.

- Implementation Challenges: Interoperability among civilian and military partners must happen at the local, state and federal level as part of a successful CAD and traffic monitoring implementation, but PII and other data collection involving civilians is extremely difficult. Additionally, collaboration across different levels of governmental agencies with different governance structures and security policies will also pose implementation challenges.

- Cybersecurity Strategies: Consider successfully implemented and commercially available CAD and traffic monitoring systems that has robust cybersecure deployments of CAD capabilities.

\subsubsection{Roadmap}

This section is intended to capture key criteria to serve as the foundation for pilot project development and funding requests.

\subsubsection{Implementation criteria}

- Objective: Establish an authoritative source of information and single point of dispatch for multiagency coordination and collaboration during crisis and mass casualty situations.

- Capabilities: Provide a shared CAD platform that serves as the informational and operational hub for multiagency response operations that is able to ingest and display various data sources from various agencies at the speed of relevance. Shows individual responder and vehicle locations in real time in the CAD map and tracks what is happening and where the emergency is coming from. Responders equipped with body cam provides visibility to the Commander on what is happening on the ground through the CAD platform.

- Pilot Design \& Metrics: Dispatches emergency responders within 1 minute of receiving call and arrive 7 minutes to location.

- Facility Considerations: Connectivity in the cantonment areas is challenging. Hard to locate people inside military installations after they call 911 from a building. In a large facility, it is even hard to find which floor the 911 caller is located.

- Lifecycle Considerations: Software and hardware updates must be maintained, and databases constantly updated. Additional costs in 
system monitoring, support, and licensing may be required for system sustainment.

- Cybersecurity Considerations: Databases containing DoD personnel information, military base infrastructure, traffic control systems, asset locations and movement of people and vehicles during crisis situations would be a prime target for malicious actors.

- Project Team Considerations: ERDC-CERL CAD Teams, ERDCITL Cybersecurity Team, military installation representatives, Program Executive Office- Intelligence, Electronic Warfare \& Sensors, Office of the Provost Marshall General, Office of the Assistant Secretary of the Army for Installations, Energy and Environment [ASA(IE\&E)].

\subsubsection{Milestones}

- Subtask 1: Establish stakeholder working group with key representatives from the entire installation ecosystem for the purpose of developing relevant pilot scenarios and criteria for selecting CAD and traffic monitoring solutions as part of the use-case demonstration. Survey current CAD and traffic monitoring best practices.

- Subtask 2: Develop solicitation with specifics for Pilot Technology Demonstration(s) and submit request for proposals/quotations (RFPs/RFQs).

- Subtask 3: Develop contracting package to include scope of work and specific base bid and option tasks for specific facilities, functionalities, and deliverables associated with the pilot effort following site coordination using existing installation staff contacts and established stakeholder relationships.

- Subtask 4: Perform detailed CAD assessments following pilot contract award and determine existing command and control infrastructure improvements to ensure data integrity and availability necessary to provide $\mathrm{CAD}$ and traffic monitoring functionality.

- Subtask 5: Provide network, system, connectivity, policies and procedural testing, training, quality assurance, and hand-off of new CAD integrated solution to enable successful transition (e.g., dashboard visualization, asset and personnel tracking capabilities, operational response sequences, etc.).

- Subtask 6: perform data collection and analysis in accordance with criteria provided by CAD working group to determine successful performance objectives including BCA. 
- Subtask 7: package results into final report/publications, facility criteria recommendations, lessons learned summaries, and next steps language.

\subsubsection{Acquisition recommendations}

- Contracting Vehicle Options: CERL,BAA.

- Period of Performance: Approximately 18 months.

- 3 months for project development.

○ 11 months for multiple scenario development.

- 1 year of daily data collection.

- 3 months for data analysis and report generation.

\subsubsection{Stakeholder information}

- Coordination required from selected installation sites and relevant Program Executive Officers (PEOs).

- Installation: Fort Benning.

- Contract POC: TBD.

\subsubsection{Assumptions and other considerations}

- The CAD use cases are built around standard installations or locations that closely mirror a standard installation.

- Existing use cases will augment any existing emergency response network to enable advanced action-oriented command and control features for increases in overall operational effectiveness.

- Multiple use-case scenarios may be required for CAD enterprise implementation.

\subsubsection{Business case analysis}

\subsubsection{Cost framework}

- Cost data to be collected will include initial hardware/software procurement, cybersecurity authorization costs, costs for repairs/improvements identified, training costs, and if applicable, annually recurring support/licensing costs.

- Savings data to be collected will include: the cost of each installation establishing its own standalone emergency responder network. 
- Data analysis will include emergency response time metrics, project cost savings scenarios, and life cycle cost analysis with annualized costs.

- The projected time line for this project is 18 months.

\subsubsection{Alternatives}

- Status Quo: Status quo at installations on average is assumed to be simply the absence of a CAD and traffic monitoring platform with no emergency responder network.

- Alternative Courses of Action (COAs): Includes outsourcing the entire capability to $3^{\text {rd }}$ party vendor who will provide the service as needed.

- COA selection: Will be based on competitive procurement and availability of funds for additional funding of contract options.

- Pilot technologies and COAs are expected to support the following:

- Alignment to mission: Facilitating cost-effective emergency response network to enable an installation-level smart and multiagency COP to support Army lines of effort for Modernization, Readiness, Reform, and People.

- Support to personnel and community: CAD and traffic monitoring can improve early detection of emerging crisis and reduce response times to critical situations providing a safe environment for installation civilians and Service members and their surrounding communities.

- Modernize infrastructure: The CAD concept requires investment in network infrastructure to be able to connect different agencies and more fully realize the benefits of a holistic solution that addresses many capability gaps, such as weak connectivity in many cantonment areas.

- Enable information sharing: CAD technologies will facilitate more standardized reporting, database integration, detailed analytics, and greater information sharing and interoperability among U.S. Government agencies at the local, State and Federal level.

\subsubsection{Risk assessment \& mitigation strategies}

- Technical Risks: Cybersecurity criteria for CAD systems require multiagency coordination and collaboration which could bring about potentially conflicting governance structure, data sharing policies and 
procedures and other security issues that has the potential to delay demonstration efforts.

- Mitigation Strategy: Engage stakeholders at the onset to assist in shaping the requirements, developing and implementing CAD use case and finally, advocating for the project.

- Cost Risks: Costs risks are medium due to the uncertainty in specific levels of efforts required from various agencies.

- Mitigation Strategy: Include contract options that best facilitate tailoring project award to availability of funding.

- Business or Operational Risks: CAD necessitates integration of various databases and data sources which could cause disruptions to ongoing operations and security processes.

- Mitigation Strategy: Include emergency response and security training and regularly scheduled O\&M progress meetings into project scope and investigate technical feasibility of data sharing among different agencies at the onset.

- Adversary Risks: Increased access of databases at the Federal, State and Local level may create additional cybersecurity vulnerabilities to be capitalized on by adversarial entities.

- Mitigation Strategy: Comply with all cybersecurity requirements and include all impacted stakeholders in project updates throughout the duration of the pilot period of performance.

\subsubsection{Return on investment}

Table 2-14 lists the anticipated quantifiable and non-quantifiable benefits of the pilot technology.

Table 2-14. CAD benefits breakdown.

\begin{tabular}{|l|l|}
\hline Anticipated Quantifiable Benefits & Anticipated Non-Quantifiable Benefits \\
\hline \multirow{3}{\$}{$\begin{array}{l}\text { - Save lives } \\
\text { - Provide unified COP } \\
- \text { Coordination and collaboration occur among } \\
\text { stakeholders and responders prior to crisis. }\end{array}$} \\
\hline
\end{tabular}

\subsection{Frictionless entry}

\subsubsection{Technology description}

Frictionless Entry provides secure and efficient installation access by speeding the process of the inspection and vetting of individuals and vehicles coming into military installations while maintaining compliance with all existing and emerging security policies. Technology solutions include sensors, 
systems as well as tactics, techniques, and procedures (TTPs) and leverage to the largest extent possible, existing programs of record, automation, and integrate emerging capabilities into an artificial intelligence platform.

\subsubsection{Summary of technology capabilities, outcomes, and challenges}

Based on a review of RFI responses from industry and Industry Day activities, Table 2-15 provides a summary of current installation facility-related capabilities, outcomes, and implementation or operational challenges associated with this technology.

Table 2-15. Summary of frictionless technology capabilities, opportunities, and challenges.

\begin{tabular}{|c|c|c|}
\hline Capabilities & Outcomes & Challenges \\
\hline (What can it do?) & $\begin{array}{c}\text { (What are the potential } \\
\text { benefits?) }\end{array}$ & $\begin{array}{c}\text { (implementation \& } \\
\text { operational challenges) }\end{array}$ \\
\hline $\begin{array}{l}\text { - Allowing secure and efficient } \\
\text { installation access without } \\
\text { needing to stop at the gate of any } \\
\text { military base to show identification } \\
\text { to the security personnel }\end{array}$ & $\begin{array}{l}\text { - Labor cost savings at } \\
\text { around } \$ 250-\$ 600 M \\
\text { per year } \\
\text { - } \text { Minimizes potential } \\
\text { COVID-19 and other } \\
\text { infectious disease } \\
\text { transmission } \\
\end{array}$ & $\begin{array}{l}\text { - Face recognition at a } \\
\text { distance on the move } \\
\text { remains challenging } \\
\text { technologically }\end{array}$ \\
\hline $\begin{array}{l}\text { - Ability to perform facial recognition } \\
\text { on the move at a significant } \\
\text { distance from the entry control } \\
\text { point } \\
\text { - Match vehicle license, make and } \\
\text { model with facial recognition } \\
\text { - Capacity to work at scale, vetting } \\
\text { at least } 3 \text { billion entries per year } \\
\text { (enterprise wide) with } \sim 45,000 \\
\text { denied entries into installations } \\
\text { with a whole range of adjudication }\end{array}$ & $\begin{array}{l}\text { - Improves speed of } \\
\text { entry } \\
\text { - } \text { Protects from COVID- } \\
19 \text { transmission } \\
\text { - } \text { Provides multiple } \\
\text { vetting methodologies } \\
\text { - Ensures sufficient } \\
\text { system capacity for } \\
\text { processing } \\
\text { - } \text { Cross-checks entries } \\
\text { with various } \\
\text { databases, i.e., FBI, } \\
\text { violations, etc. }\end{array}$ & $\begin{array}{l}\text { - Requires a minimum } \\
\text { amount of distance to } \\
\text { recognize face } \\
\text { - Requires organizational } \\
\text { and personnel change } \\
\text { - Need to compile data \& } \\
\text { maintain timely } \\
\text { database updates } \\
\text { - Existing data integrity } \\
\text { and integration issues } \\
\text { - Collection and sharing } \\
\text { of PII is challenging } \\
\text { among civilians }\end{array}$ \\
\hline
\end{tabular}

\subsubsection{Industry Day summary}

\subsubsection{Use-case proponent}

- Fort Benning Garrison.

- Joint Base Myer-Henderson Hall.

\subsubsection{Summary topics}

- Balance Risk with Cost: risk must be measured against cost. Government must determine how secure it wants to be, and how much funding is it willing to spend. 
- Hybrid Solution: Government must consider a hybrid solution in balancing speed and price point. It is doable in today's technology to have the same ease of access along the same efficiency as EZ Pass.

- Triangulated Vetting: Solution requires a combination of license plate recognition (LPR) technology, facial recognition, and pre-registered mobile device for a two- or three-factor authentication.

- Implementation Challenges: Proper policies and procedures need to be in place as part of a successful Frictionless Entry technology implementation.

- Cybersecurity Strategies: Commercially available frictionless entry technology solutions must take into consideration cybersecurity in ensuring personal information are securely maintained and protected.

\subsubsection{Roadmap}

\subsubsection{Implementation criteria}

- Objective: Positively identify individuals entering installation without needing to stop at the gate. Utilize the same level of security requirements from current vetting operations and maintain the same level of compliance with all existing and emerging security policies.

- Capabilities: Software to alert, in real time, any unauthorized individuals entering installations. Establish semi-automated adjudication process for denied entries for secure, consistent, and cost-effective operation.

- Pilot Design \& Metrics: Conduct baseline intervention demonstration method to:

- Pilot 1. Positively Identify Without Stopping. Create a database of 10 people. Train system to recognize 10 people. Test the 10 drivers with Automated Installation Entry (AIE) using a simultaneous combination of Facial and License Recognition Technology.

- Pilot 2. Positively Identify By Stopping and Providing Biometrics. Using the same databases, classify five people as unauthorized personnel. System must flag unauthorized personnel.

- Pilot 3. Positively Identify authorized and unauthorized personnel in the same vehicle.

- Facility Considerations: In supporting personnel data collection/analysis entering the base, the system must be able to handle more than 3 billion entries yearly. Out of 3 billion, approximately 45,000 individuals are denied entry into installations yearly and 
undergo a whole range of adjudication. System must be able to handle this minimum level of scale and complexity.

- Lifecycle Considerations: Software and hardware updates must be maintained, and databases constantly updated. Additional costs in system monitoring, support, and licensing may be required for system sustainment.

- Cybersecurity Considerations: Databases containing DoD personnel and visitor information would be a prime target for malicious actors. When Personally Identifying Information (PII) are cross-checked with other Federal and State databases, network cybersecurity must be robust and up-to-date at military checkpoints.

- Project Team Considerations: ERDC-CERL Frictionless Entry Teams, ERDC-ITL Cybersecurity Team, military installation representatives, Program Executive Office- Intelligence, Electronic Warfare \& Sensors, Office of the Provost Marshall General, Office of the Assistant Secretary of the Army for Installations, Energy and Environment [ASA(IE\&E)].

\subsubsection{Milestones}

- Subtask 1: Develop criteria for selecting frictionless entry technology solutions as part of demonstrations: survey current AIE best practices.

- Subtask 2: Develop contracting package to include scope of work and specific base bid and option tasks for specific facilities, functionalities, and deliverables associated with the pilot effort following site coordination using existing installation staff contacts and established stakeholder relationships.

- Subtask 3: Perform detailed frictionless entry assessments following pilot contract award and determine existing controls infrastructure improvements to ensure data integrity and availability necessary to provide Frictionless Entry functionality.

- Subtask 4: Provide installation, testing, training, quality assurance, and hand-off of new software and hardware required to enable successful transition of Frictionless Entry solution (e.g., dashboard visualization, automated demand response sequences, predictive analytics, semi-automated adjudication process, etc.).

- Subtask 5: Perform data collection and analysis in accordance with criteria provided by security policies and procedures to determine successful performance objectives including BCA.

- Subtask 6: Package results into final report/publications, facility criteria recommendations, lessons learned summaries, and next steps language. 


\subsubsection{Acquisition recommendations}

- Contracting Vehicle Options: CERL, or local MICC.

- Period of Performance: Approximately 18 months.

○ 3 months for project development.

○ 11 months for multiple scenario development.

- 1 year of daily data collection.

- 3 months for data analysis and report generation.

- Contracting Scope Recommended: recommend 3 initial facilities connected to a common installation with additional State and Federal partners to test various scenarios as desired.

\subsubsection{Stakeholder information}

- Coordination required from Army Strategic Integration, U.S. Army Installation Management, Select Military Installations, ASA(IE\&E), PEO for Intelligence, Electronic Warfare and Sensors (IEW\&S), Office of the Provost Marshall General.

- Installation: TBD.

- Contract POC: TBD.

\subsubsection{Assumptions and other considerations}

- The Frictionless Entry use cases are built around standard installations or locations that closely mirror a standard installation.

- Existing use cases will augment existing security policies and procedures for unauthorized entries to enable advanced action-oriented control features for increases in overall installation management effectiveness.

- Multiple use-case scenarios based on various gate security systems and protocols may be required for enterprise implementation.

\subsubsection{Business case analysis}

\subsubsection{Cost framework}

- Cost data to be collected will include initial hardware/software procurement, cybersecurity authorization costs, costs for repairs/improvements identified, and if applicable, annually recurring support/licensing costs.

- Savings data to be collected will include before-and-after labor cost data and avoided equipment. 
- Data analysis will include linear regression of labor cost based on significant event normalization, base entry flow modeling as needed to project savings scenarios, and life cycle cost analysis with annualized costs.

- The projected time line for this project is 30 months.

\subsubsection{Alternatives}

- Status Quo: Status quo at installations on average is assumed to be maintaining the $100 \%$ reliance on security personnel at checkpoints.

- Alternative Courses of Action (COAs): May include a semi-automated frictionless entry solution that includes a combination of security personnel and facial and license recognition technology.

- COA selection: Will be based on competitive procurement and availability of funds for additional funding of contract options.

- Pilot technologies and COAs are expected to support the following:

- Alignment to mission: Facilitating cost-effective connection to legacy policies and procedures to enable installation-level smart frictionless entry capabilities to support Army lines of effort for Modernization, Readiness, Reform, and People.

- Support to personnel and community: Frictionless Entry technologies can improve consistent detection of unauthorized personnel particularly those riding in the same vehicle with an authorized personnel. Reduce waiting time at entry checkpoints particularly during rush hours for installation civilians and Service members.

- Modernize infrastructure: The Frictionless Entry requires investment in artificial intelligence platforms, particularly critical in ensuring consistent and reliable reporting and security enforcement procedures during pandemics and other crisis situations when frontline security personnel may be impacted.

- Enable information sharing: Frictionless entry technologies will enable more standardized database integration, detailed analytics, and advanced information sharing among U.S. Government agencies. Flagging repeat offenders through improved user interface feature would enable action-oriented security recommendations.

\subsubsection{Risk assessment \& mitigation strategies}

- Technical Risks: Cybersecurity criteria for frictionless entry solution systems require multiagency coordination and collaboration that has the potential to delay demonstration efforts. 
- Mitigation Strategy: Engage stakeholders to assist in advocating for the project.

- Cost Risks: Costs risks are medium given that frictionless entry solutions are already implemented in private industry, however there is uncertainty in specific levels of efforts required by each military installations to provide these capabilities.

- Mitigation Strategy: Include contract options that best facilitate tailoring project award to availability of funding (e.g., 12 base bid facilities, 4 option task bids).

- Business or Operational Risks: Frictionless entry benefits necessitate integration into existing installation O\&M workflow and security processes.

- Mitigation Strategy: Include security training and regularly scheduled O\&M progress meetings into project scope and investigate technical feasibility of data sharing among different agencies.

- Adversary Risks: Increased networking of databases at the Federal and State level may create additional cybersecurity vulnerabilities to be capitalized on by adversarial entities.

- Mitigation Strategy: Comply with all cybersecurity requirements and include all impacted stakeholders in project updates throughout the duration of the pilot period of performance.

\subsubsection{Return on investment}

Table 2-16 lists the anticipated quantifiable and non-quantifiable benefits of the pilot technology.

Table 2-16. Frictionless entry quantifiable \& non-quantifiable benefits.

\begin{tabular}{|l|l|}
\hline Anticipated Quantifiable Benefits & Anticipated Non-Quantifiable Benefits \\
\hline \$250-\$600M labor cost savings per year & Avoids COVID-19 transmission at Gate \\
\hline
\end{tabular}

\subsection{Automated assessments}

\subsubsection{Technology description}

Automated Facility Assessments will enable either near real-time distress detection or technology to assist inspection personnel in the assessment of condition and determine any areas of deterioration or distress (Figure 2-3). 
Figure 2-3. Demonstration of two Video Analytics software.

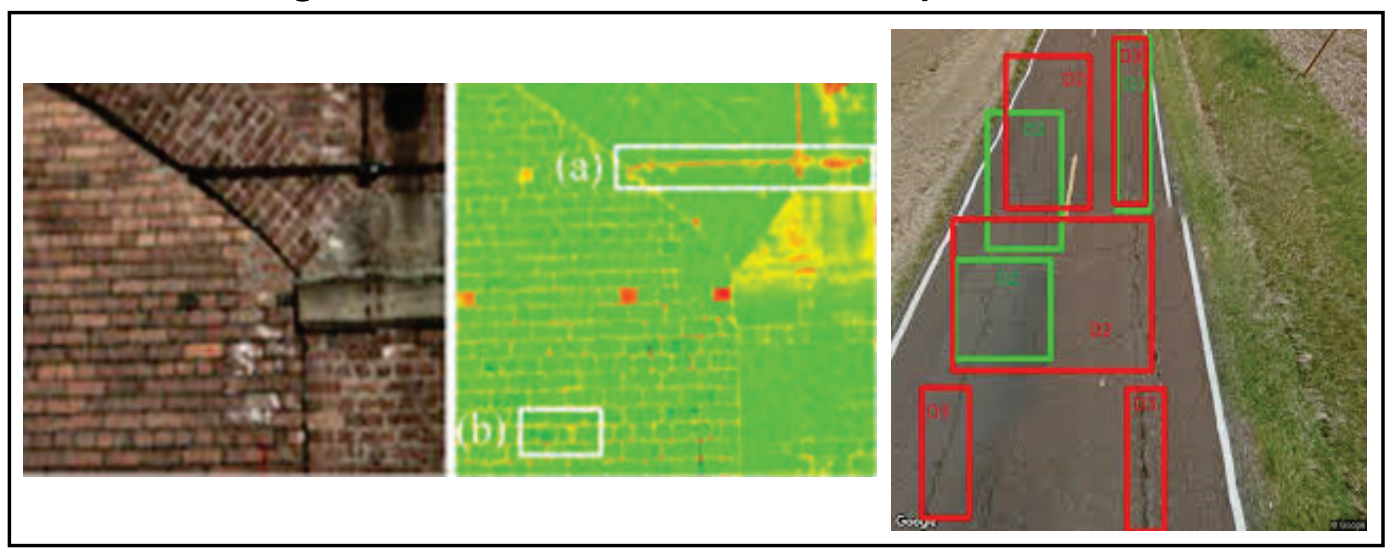

\subsubsection{Summary of technology capabilities, outcomes, and challenges}

Based on a review of RFI responses from industry and Industry Day activities, Table 2-17 summarizes current installation facility-related capabilities, outcomes, and implementation or operational challenges associated with this technology.

Table 2-17. Summary of automated facility assessment technology capabilities, opportunities, and challenges.

\begin{tabular}{|c|c|c|}
\hline Capabilities & Outcomes & Challenges \\
\hline (What can it do?) & $\begin{array}{c}\text { (What are the potential } \\
\text { benefits?) }\end{array}$ & $\begin{array}{c}\text { (Implementation \& operational } \\
\text { challenges) }\end{array}$ \\
\hline $\begin{array}{l}\text { - Video Analytics: access } \\
\text { component distresses or } \\
\text { changes } \\
\text { - Remote Sensors: Gather } \\
\text { data about components } \\
\text { through new or existing } \\
\text { automation systems } \\
\text { - Remote Sensing: } \\
\text { Inspectors use handheld } \\
\text { remote sensing devices }\end{array}$ & $\begin{array}{l}\text { - } \text { Reduce workforce } \\
\text { required to update } \\
\text { infrastructure } \\
\text { conditions reports } \\
\text { - Enhance situational } \\
\text { awareness of areas of } \\
\text { deterioration that } \\
\text { impact the mission } \\
\text { - Provide more accurate } \\
\text { reporting of } \\
\text { infrastructure } \\
\text { conditions for readiness }\end{array}$ & $\begin{array}{l}\text { - Prioritization of which specific } \\
\text { distresses are most important } \\
\text { to train the Video Analytics } \\
\text { algorithms to detect and predict } \\
\text { - Immature technology } \\
\text { - Prioritization of which sensing } \\
\text { devices to pilot and which } \\
\text { distress detection or anomalies } \\
\text { are aligned with that sensing } \\
\text { technology }\end{array}$ \\
\hline
\end{tabular}

\subsubsection{Industry Day summary}

\subsubsection{Use case proponent}

- Fort Benning. 


\subsubsection{Summary topics}

- Communication: Of important note in this presentation was the level of communication between the Government and Industry. Due to the breadth of the topic area, in which dozens of potential use cases could be derived, the session responses and discussions were very general. The majority of the presentation consisted of Industry listening to the perspectives of the Government representatives, and little dialogue back from Industry. Overall, the participation in the session was quite large with over 100 Industry representatives.

- Video Analytics: Use of Video Analytics to assess component distresses or changes.

- Remote Sensors: Remote sensors, which are newly installed, or data is gathered from building automation system sensors that are already in place.

- Remote Sensing: Remote sensing devices which are operated by a physical person during an assessment such as thermal infrared.

\subsubsection{Roadmap}

Due to the maturity of the Video Analytics technologies in Industry and the relative newness of the Remote Sensor and Remote Sensing technologies, the focus of the pilot should be Video Analytics. The Remote Sensors and Remote Sensing technologies will be briefly mentioned to show the beginnings of the ideas which need to be expanded upon in the future.

\subsubsection{Implementation criteria}

\subsection{Video analytics}

- Objective: Evaluate the use of either existing cameras (i.e., security cameras) or newly installed cameras, which detect distress information for building or other infrastructure components. Many industry participants alluded to technologies that are available to perform this type of analysis and noted that these technologies are ready right now.

- Capabilities: Near real-time gathering and analysis of infrastructure component data which can identify inventory, condition, distresses, or other fault detection. Outcome data should be able to align with DoD enterprise assessment applications such as the SMS applications.

- Pilot Design \& Metrics: Conduct a baseline intervention demonstration method to measure reduction in workforce, enhanced situational awareness, and improved accuracy of facility reports. 
- Facility Considerations: To support video data collection and analysis, facilities with existing video surveillance or the desire to install video surveillance, central monitoring of video surveillance, or with video surveillance that also has facility or infrastructure in view should be targeted. For economy of scale cost-effectiveness, conduct pilots with facilities located on a single Army installation.

- Lifecycle Considerations: There are no special disposal costs (software and minor hardware only), however additional system monitoring, support, and licensing may be required as part of cybersecurity criteria and Automated Facility Assessment system sustainment.

- Cybersecurity Considerations: RMF is required per UFC 4-010-06 Cybersecurity of Facility-Related Control Systems.

\subsection{Remote sensors}

- Objective: Evaluate the use of multiple remote sensors / devices to monitor and track various distress elements of infrastructure components. These could be newly installed sensors, existing sensors which are part of a building automation system, or a mix of both which are aggregated together for analysis.

- Capabilities: Develop a set of real-time data and analytics which can identify distresses, faults or other anomalies in infrastructure components. The data and analytics should be non-proprietary with the ability of being able to access raw data for use in other government research surrounding the Installations of the Future business area.

\subsection{Remote sensing}

- Objective: Evaluate the use of handheld remote sensing devices such as thermal infrared, LiDAR, photogrammetry, RGB, or other sensing devices which would allow an inspector to gather anomalies surrounding infrastructure components which can be mapped to physical distresses.

- Capabilities: A desired outcome might be an in-depth case study of what remote sensing technologies are available, what data can be collected from those technologies, and how that data can be mapped to distress or fault information. Following the industry case study, a pilot demonstration of the top technologies could be carried out. The data and analytics should be non-proprietary with the ability to be able to access raw data for use in other government research surrounding the Installations of the Future business area. 


\subsubsection{Milestones}

- Subtask 1: Development of criteria for selecting which video monitoring systems to focus on for the pilot.

- Subtask 2: Development of Automated Facility Assessment contracting package.

- Subtask 3: Perform detailed conditions assessment of facility to be monitored to develop a baseline.

- Subtask 4: Provide installation, testing, training, quality assurance, and hand-off of new software and minor hardware required to enable Automated Facility Assessments capabilities.

- Subtask 5: Perform data collection and analysis at prescribed schedules and in accordance with the criteria provided to determine successful performance objectives including BCA.

- Subtask 6: Package results into final report/publications, facility criteria recommendations, lessons learned summaries, and next steps language.

\subsubsection{Acquisition recommendations}

- Contracting Vehicle Options: CERL BAA, OTA, or USACE Huntsville MATOC.

- Period of Performance: 38 Months.

- 30 days for RFP.

- 8 months for contract award.

○ 18-month demonstration period.

o 12-month Engineering/RMF certification.

- Contracting Scope Recommended: Ensure that at least one asset in each UFC Facility Analysis Category (FAC) Class is monitored. The minimum number of facilities to be monitored would therefore be eight.

\subsubsection{Stakeholder information}

- Installation: TBD.

- Contract POC: TBD.

\subsubsection{Assumptions and other considerations}

- Video Analytics: The pilot should leverage existing video analysis technology to detect distresses and the focus of the pilot would be on the automated integration with the SMS applications. 
- Remote Sensors: The deployment of the remote sensors whether standalone or part of an existing building automation system should be a routine execution (i.e., no new technology). However, the development in this pilot would be focused on the middle layer decision process, which correlates the sensor information into specific component level distress information in the SMS applications.

- Remote Sensing: The deployment of the remote sensing assessments should be a routine execution (i.e., no new technology). However, the development in this pilot would be focused on the middle layer decision process, which correlates the sensor information and outputs into specific component level distress information in the SMS applications.

\subsubsection{Business case analysis}

\subsubsection{Cost framework}

- Cost data to be collected will include initial hardware/software procurement, RMF cybersecurity authorization costs, costs for repairs/improvements identified, and annually recurring support/licensing costs.

- We expect Automated Facility Assessments to reduce the labor that is currently required to assess the state of facilities. We will determine the payback by interviewing individuals who currently do these assessments to determine the amount of time that could be saved and the labor rates of those individuals.

- Data analysis will include validation between existing facility condition assessment (FCA) practices and the amount of automated analytics are able to be obtained from this pilot.

- Period of data collection will include 1.5 years of monthly data collection.

\subsubsection{Alternatives}

Pilot technologies are expected to support the following:

The Army is looking toward the future, in particular, the emerging role that technology can play in the modernization and reformation of installation operations.

- Alignment to mission: Video analytics technologies will enhance the resilience and readiness of Army installations by providing information about what facilities need improvement. 
- Support to personnel and community: Real-time monitoring and alert system will improve the safety of facilities allowing service members to focus on their mission.

- Modernize infrastructure: By understanding the facilities in need of improvement, maintenance personnel can improve aging infrastructure and modernize out-of-date facilities.

- Enable information sharing: Video analytics data will be used by the SMS technologies to enable information sharing throughout DoD.

- Energy reduction: By understanding the facilities in need of improvement, maintenance personnel can focus efforts and energy and repair the worst damages before it becomes a bigger problem.

\subsubsection{Risk assessment \& mitigation strategies}

- Technical Risks: Cybersecurity criteria for facility video surveillance systems require project-tailored RMF costs, coordination, and system configuration that has the potential to delay demonstration efforts.

- Mitigation Strategy: Engage the USACE Army Control System Cybersecurity Mandatory Center of Expertise (CSC-MCX) to lead RMF tailoring efforts and continuous monitoring processes.

- Cost Risks: Low due to capability of tailoring to fit budget and use of previously installed hardware.

- Mitigation Strategy: Include contract options that best facilitate tailoring project award to availability of funding (e.g., 12 base bid facilities, 4 option task bids).

- Business or Operational Risks: Automated Facility Assessments benefits necessitate integration into existing installation facility assessment workflow processes.

- Mitigation Strategy: Clear definitions of the standards and policies for automated distress workflow processes as well as additional workflow processes for quality control (QC) of automated assessment detection processes.

\subsubsection{Return on investment}

Table 2-18 lists the anticipated quantifiable and non-quantifiable benefits of the pilot technology. 
Table 2-18. Benefits breakdown of the pilot technology.

\begin{tabular}{|c|l|}
\hline Anticipated Quantifiable Benefits & Anticipated Non-Quantifiable Benefits \\
\hline $\begin{array}{l}\text { - Increased detection of facility change } \\
\text { and distress }\end{array}$ & - Improved maintenance personnel effectiveness \\
\hline- & - Improved resilience and readiness \\
\hline- & $\begin{array}{l}\text { Data sharing to develop models for facility } \\
\text { deterioration over time }\end{array}$ \\
\hline
\end{tabular}

\subsection{Child Development Center (CDC) Video Analytics}

\subsubsection{Technology description}

CDCs support readiness by reducing the conflict and easing the stress of balancing parental responsibilities with mission requirements. CDCs operate in a highly-regulated environment and must meet statutory requirements for national accreditation including ratio management, access control, and child tracking, just to name a few, to receive DoD certification (equivalent to state licensing) to operate.

The Smart Child Development Center pilot program will take advantage of video surveillance and analytics technology capabilities (Figure 2-4) to provide automated support for some of these requirements. The effort will utilize video surveillance data collected at CDCs processed via machine learning focused on broad spectrum and targeted data analytics to provide timely and targeted child care informatics services, demonstrating a capability that can subsequently be translated into practice in other Army CDC environments. The use of video surveillance system (VSS) will support management and staff by providing:

- Risk Management.

- Behavior Assessment.

- Classroom Operations Monitoring.

- Facility Operations Monitoring.

The Smart CDC analytics technology will supplement processes already in place to ensure and enhance the safety and well-being of children/youth in Child and Youth Services (CYS) programs, providing an efficient and systematic safeguard and analytics platform for DoD childcare programs. 
Figure 2-4. Smart Child Development Center pilot program will take advantage of video surveillance and analytics technology capabilities.

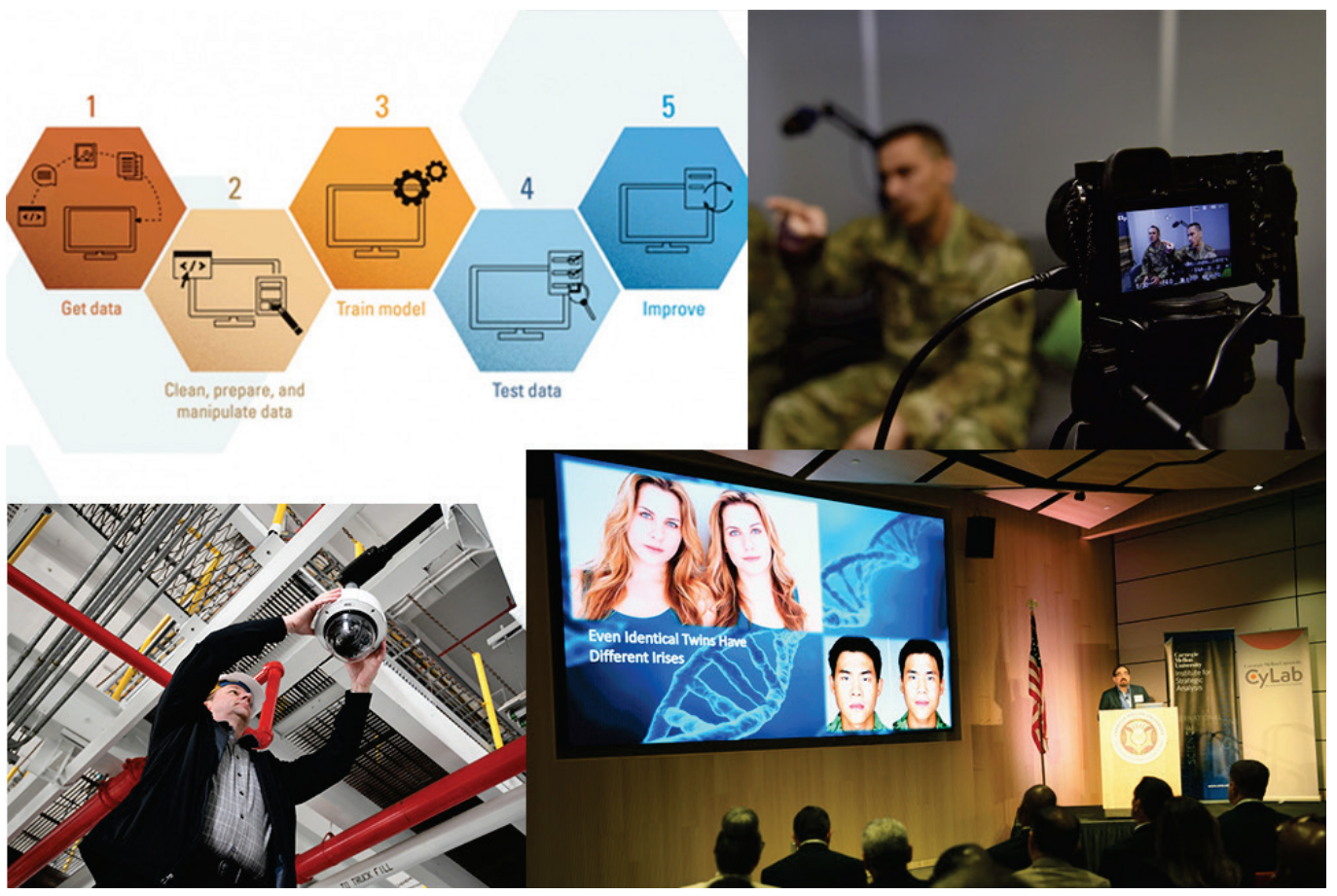

\subsubsection{Summary of technology capabilities, outcomes, metrics, \& challenges}

Based on a review of RFI responses from industry and Industry Day activities, Table 2-19 provides a summary of current installation facility-related capabilities, outcomes and metrics. 
Table 2-19. Summary of Smart CDC Video Analytics technology capabilities, opportunities, and challenges.

\begin{tabular}{|c|c|c|}
\hline Capabilities & Outcomes & Challenges \\
\hline (What can it do?) & (What are the potential benefits?) & $\begin{array}{c}\text { (Implementation \& operational } \\
\text { challenges) }\end{array}$ \\
\hline $\begin{array}{l}\text { 1. Risk } \\
\text { Management: } \\
\text { (a) Ratios / } \\
\text { Accountability }\end{array}$ & $\begin{array}{l}\text { - To implement mitigation } \\
\text { strategies that support Life, } \\
\text { - } \text { Identety, Health factors in a CDC. } \\
\text { mandated ratio requirements. } \\
\text { - Children are accounted for } \\
\text { during drills and group } \\
\text { movements between locations. } \\
\text { - Facial recognition used to } \\
\text { identify teaching staff/ parents } \\
\text { /guardians /emergency } \\
\text { designees. } \\
\text { - Parents sign their children into } \\
\text { and out of classrooms. } \\
\text { - Teachers are signed into and } \\
\text { out of classrooms for shifts, } \\
\text { and any other time they leave } \\
\text { and re-enter the room and have } \\
\text { nametags and identifying } \\
\text { apparel. } \\
\text { - Front and back doors of } \\
\text { classrooms can be monitored. } \\
\text { - Identify/flag if one teacher is } \\
\text { left alone with one student. } \\
\text { - Identify if any child/children is } \\
\text { out of a line of sight of a } \\
\text { teacher. }\end{array}$ & $\begin{array}{l}\text { - Upgrading current technologies } \\
\text { onsite to ensure that new Video } \\
\text { Surveillance System (VSS) has } \\
\text { enough sensing capabilities to } \\
\text { capture all targeted areas. } \\
\text { - Ensuring storage capabilities are } \\
\text { adequate for required Video } \\
\text { Analytics (for onsite storage } \\
\text { requirements). } \\
\text { - Data security, particularly PII security } \\
\text { is a central consideration that could } \\
\text { pose a challenge depending on what } \\
\text { technologies and data storage } \\
\text { methods would be utilized. } \\
\text { - Potential Installation /Staff /Parent } \\
\text { discomfort with the facial } \\
\text { recognition and biometric } \\
\text { technologies required for the Video } \\
\text { Analytics would need to be } \\
\text { recognized and addressed. The pilot } \\
\text { installation is planning to provide } \\
\text { information sessions prior to start of } \\
\text { the pilot project in order to ensure } \\
\text { that all are on-board before the pilot } \\
\text { project is underway. }\end{array}$ \\
\hline $\begin{array}{l}\text { (b) Medical \& } \\
\text { Sudden Infant } \\
\text { Death Syndrome } \\
\text { (SIDS) }\end{array}$ & $\begin{array}{l}\text { - To implement mitigation } \\
\text { strategies that support Life, } \\
\text { Safety, Health factors in a CDC. } \\
\text { - Identify instances and duration } \\
\text { of infants left alone or when } \\
\text { caregivers are facing away. } \\
\text { - Identify children who need } \\
\text { rescue medication or have food } \\
\text { allergies. } \\
\text { - Track response time for infant } \\
\text { crying/distress/or medical } \\
\text { emergency. } \\
\text { - Identify periods of non- } \\
\text { movement in sleep (SIDS } \\
\text { prevention). }\end{array}$ & \\
\hline
\end{tabular}




\begin{tabular}{|c|c|c|}
\hline Capabilities & Outcomes & Challenges \\
\hline (What can it do?) & (What are the potential benefits?) & $\begin{array}{c}\text { (Implementation \& operational } \\
\text { challenges) }\end{array}$ \\
\hline $\begin{array}{l}\text { 2. Behavior } \\
\text { Assessment: } \\
\text { (a) Teacher } \\
\text { Behavior }\end{array}$ & $\begin{array}{l}\text { - To identify potentially harmful } \\
\text { teacher behaviors in order for } \\
\text { managers to quickly address } \\
\text { and develop training in order to } \\
\text { support positive interactions } \\
\text { between teachers and children. } \\
\text { - Identify raised teacher voices. } \\
\text { - Identify extended periods of } \\
\text { crying in Toddler and Preschool } \\
\text { classrooms. } \\
\text { - Identify body language and } \\
\text { facial expressions that } \\
\text { demonstrate stress. } \\
\text { - Identify discipline methods. }\end{array}$ & \\
\hline $\begin{array}{l}\text { (b) Child } \\
\text { Behavior }\end{array}$ & $\begin{array}{l}\text { - To identify high activity } \\
\text { behaviors from children in } \\
\text { order to support environmental } \\
\text { changes that are needed in } \\
\text { classrooms. } \\
\text { - Identify if children are on top of } \\
\text { furniture. } \\
\text { - Identify running in classrooms. } \\
\text { - Identify if children are engaging } \\
\text { in rough play. } \\
\text { - Identify developmental } \\
\text { readiness of children for } \\
\text { transitions to the next } \\
\text { classroom. } \\
\text { - Identify developmental delays. }\end{array}$ & \\
\hline $\begin{array}{l}\text { 3. Classroom } \\
\text { Operations } \\
\text { Monitoring: } \\
\text { (a) Environment }\end{array}$ & $\begin{array}{l}\text { - Social and emotional support } \\
\text { for children, increased } \\
\text { communication between } \\
\text { teacher and child, } \\
\text { developmentally appropriate } \\
\text { environments, possible } \\
\text { predictor of developmental } \\
\text { delays if children do not } \\
\text { participate in activities } \\
\text { - Child appropriate furniture } \\
\text { (function and safety) } \\
\text { - Shelves are stocked with } \\
\text { materials } \\
\text { - Displays on the walls } \\
\text { - Books and the book shelves } \\
\text { - Cots } 3 \text { feet apart during } \\
\text { naptime }\end{array}$ & \\
\hline
\end{tabular}




\begin{tabular}{|c|c|c|}
\hline Capabilities & Outcomes & Challenges \\
\hline (What can it do?) & (What are the potential benefits?) & $\begin{array}{c}\text { (Implementation \& operational } \\
\text { challenges) }\end{array}$ \\
\hline (b) Teaching & $\begin{array}{l}\text { - Social and emotional support } \\
\text { for children, increased } \\
\text { communication between } \\
\text { teacher and child, } \\
\text { developmentally appropriate } \\
\text { environments, possible } \\
\text { predictor of developmental } \\
\text { delays if children do not } \\
\text { participate in activities. } \\
\text { - Identify wait times for meals or } \\
\text { transitions. } \\
\text { - Identify receptive and } \\
\text { expressive interaction between } \\
\text { children and teacher (verbal } \\
\text { and non-verbal). } \\
\text { - Identify teacher sitting on the } \\
\text { floor. } \\
\text { - Identify teachers reading. } \\
\text { - Identify times spent in activity } \\
\text { centers. } \\
\text { - Identify and monitor hygiene } \\
\text { practices. }\end{array}$ & \\
\hline
\end{tabular}

For all capabilities listed in Table 2-19, technological challenges are the same: Upgrading current technologies onsite to ensure that new VSS has enough sensing capabilities to capture all targeted areas; also ensuring storage capabilities are adequate for required Video Analytics (for onsite storage requirements). Data security is also a consideration that could pose a challenge depending on what technologies would be utilized.

\subsubsection{Industry Day summary}

\subsubsection{Use case proponent}

- Fort Jackson, supported by DCS G-9 ISE, IMCOM G-9, and ASA IE\&E Strategic Integration.

\subsubsection{Summary topics}

- Context of Army Childcare Services (including but not limited to CDCs): Provision of context by panel members to allow insight into unique aspects of military-provisioned childcare (including regulatory requirements). 
- Current State-of-Technologies and Video Surveillance Systems (VSS) on installations: Identification of what technologies are currently being utilized and what upgrades are underway/planned.

- Technology capabilities and potential usage within military context: What types of Video Analytics capabilities currently exist, and how might they be adapted and used within Army childcare facilities.

- Implementation Challenges: What types of challenges might exist when installing and utilizing a VSS system within Army childcare facilities.

- Cybersecurity Considerations: Are there any unique aspects of Army childcare facilities that would drive cybersecurity of VSS and any analytics platform.

- Other opportunities: Brainstorm of other opportunities and VSS/analytics technology applications that could benefit this use-case scenario.

\subsubsection{Roadmap}

\subsubsection{Implementation criteria}

- Objective: The Smart CDC effort will utilize video data collected at CDCs processed via machine learning focused on broad spectrum and targeted data analytics to provide timely and targeted child care informatics services, demonstrating a capability that can subsequently be translated into practice in other Army CDC environments. Utilizing (upgraded) available hardware at the proponent installation's CDC, the pilot project will provide improved processes to meet statutory requirements for national accreditation and DoD certification (equivalent to state licensing) to operate.

- Capabilities: The pilot project will ensure that video analytic targets cover a) risk management, b) behavior assessment, c) classroom operations monitoring, and d) facilities operations monitoring. For specific analytic targets for each capability, see Table 2-19 in Section 2.10.2 .

- Pilot Design \& Metrics: Data collection over a minimum 18-month period will be necessary to ensure that analytics can capture the child developmental continuum. This will ensure that the data will be useful in assisting in behavior analysis, as well as informing when children are developmentally ready for the next class level. Phased analytics could be implemented, as some of the capabilities (more monitoring-oriented versus analytics-oriented) do not need to consider the time continuum. With 
phasing, the pilot could begin collecting data and immediately provide certain controls/monitoring/surveillance feedback. Follow-on phases would be useful for behavior analytics, staff training, safety/accountability, reducing administrative burdens, accreditation support, as well as cost control through analytics. Metrics are listed in Table 2-19, and include measure targets for effectiveness and performance.

- Facility Considerations: Each CDC is currently equipped with a VSS, without audio. VSS monitors adult/child ratios, staff/child interactions, unauthorized removal of children/youth, wandering children, observation of staff competency, training needs, and general classroom observations. It does not cover 100 percent of the facility, but rather supplements the processes already in place to ensure the safety and well-being of children/youth in CYS programs. VSS is designed to deter and reduce the risk of child abuse, protect staff from unwarranted allegations of child abuse, support management staff in exercising program oversight, and provide soldiers and parents with peace of mind allowing them to focus on their mission.

Pilot site (Fort Jackson) is a 324 capacity CDC that is currently planned to upgrade their VSS. This will improve the camera capabilities from analog (720H x 480W) to IP (Internet Protocol) with up to 5-megapixel resolution, up to 30 images per a second, integrated adaptive infrared (IR) illumination, autofocus motorized remote lens, motion detection and camera sabotage detection. Sound capabilities will also be added.

Current RAID DVR storage will be upgraded to a Pelco server. Software will be upgraded from Intellex Management Software to VxPro.

- Lifecycle Considerations: There are no special disposal costs (software and minor hardware only), however additional system monitoring, support, and licensing may be required as part of cybersecurity criteria.

- Cybersecurity Considerations: Networks/components/data will need to be secure to prevent cybersecurity intrusions. Prevention of loss of PII, facial recognition data, other intrusive breaches are paramount to prevent adversaries from threatening childcare environment, as well as for safety of Army personnel (of all rankings); all this impacts mission readiness if compromised.

- Project Team Considerations: Fort Jackson proponents remain the driving customer for the pilot program. ERDC-CERL can be 
utilized for verifying pilot specifications, assessing pilot implementation, as well as potentially translating the capabilities and system analytics created within the pilot program to other Army installations. ERDC-CERL would also assist in contracting and oversight as required.

\subsubsection{Milestones}

- Pre-contract CDC Site Work for Installation Support: During the time that the CERL BAA / Pre-contract award process is underway, proponent CDC site work should be occurring to ensure installation support and approval. This includes: Information meeting and materials for Installation chain-of-command/Commander (permissions); information meeting and materials for parents; and information meetings and materials for teachers/staff. This will ensure that once the contract is awarded, the pilot program can begin with data collection and project work.

- Project kickoff: Contractor onsite with Proponent and CDC staff to review pilot program objectives, tasks, deliverables, and schedule.

- Contractor Design for VSS and Data Analytics: Contractor to provide designs for VSS and Data Analytics system for review by Proponent CDC.

- Contractor Install (if required): If anything needs to be installed outside of the (upgraded) VSS hardware system at the CDC, this should be done here.

- Coding/Creation of initial Data Processing System/Algorithm/User Interface: The analytics software that provides the data processing algorithms and user interface should be ongoing, but with the initial validation after the $1^{\text {st }}$ month of data collection in order to validate initial processing targets. Ongoing validation and modifications to algorithms and user interface is expected.

- VSS Data Collection Commencement \& Ongoing Target Monitoring: VSS data collection must be started as early as possible to ensure the 18-month minimum data collection period (with periodic target monitoring for validation) that is expected to be required to ensure that the child development continuum is captured.

- Achievement of Risk Management Capability: This capability should be provided with a minimum of 2.5 months non-automated work period; 6 months of monitoring (automated data collection/analytics); 1.5 months adjusting coding, data processing \& synthesis; and 1 -month validation. Deliverable of final version will yield completion of this milestone. 
- Achievement of Behavior Assessment Capability: This capability should be provided with a minimum of 6 months non-automated work period; 18 months of monitoring (automated data collection/analytics); 4 months adjusting coding, data processing \& synthesis; and 2month validation. Deliverable of final version will yield completion of this milestone.

- Achievement of Classroom Operations Monitoring Capability: This capability should be provided with a minimum of 6 months non-automated work period; 18 months of monitoring (automated data collection/analytics); 4 months adjusting coding, data processing \& synthesis; and 2-month validation. Deliverable of final version will yield completion of this milestone.

- Achievement of Facility Operations Monitoring Capability: This capability should be provided with a minimum of 2 months nonautomated work period; 3 months of monitoring (automated data collection/analytics); 1 month adjusting coding, data processing \& synthesis; and 1-month validation. Deliverable of final version will yield completion of this milestone.

- Final Version VSS and Video Analytics Presentation \& Approval: Contractor will provide the final version of the VSS and Video Analytics system to proponent for review and validation. Note that for behavioral and classroom operations targets that are subjective, ongoing validation will be required with a post processing period to confirm working algorithms for final version approval. This milestone should be preceded by system framework and consolidation, as well as any final testing that is required.

- Pilot Program Wrap-Up, Report Deliverable Completed \& Lessons Learned Contractor Site Visit: Contractor to perform site visit to proponent installation to provide deliverable of the pilot program report, a presentation to share outcomes and lessons learned, and provision any necessary hand-off of technologies. This will ensure that the installation can continue to maintain the VSS and Video Analytics system for CDC support.

\subsubsection{Acquisition recommendations}

- Contracting Vehicle Options: ERDC BAA Contract Vehicle, 5 months for RFP, with 9-11 Total Months for Start of Implementation, and 25 Months for running at full mission capability. Total timeline 3436 months. 
- Period of Performance: Approximately 34-36 months (see below).

- 3 months for project development.

○ 9-11 month for contracting actions.

- 18 months for site work, data collection and parent/teacher/staff information meetings (can be done in conjunction with contracting actions).

○ 4 months for report generation.

- Contracting Scope Recommended: Pilot to be completed at Fort Jackson CDC. Additional follow-on pilots could be planned at other Army installations (chosen per consultation of all stakeholders to provide maximum impact) if Fort Jackson proves successful. See "Facility Considerations" in Section 2.10.4 to inform scope. Pilot should intend to utilize (upgraded) hardware at Fort Jackson. Scope assumes integration of new and existing algorithms to create successful analytic architecture (that would also be transferrable across DoD CDC sites) and provide responsive and easy-to-use user interface. Any additional sensors, as well as any proprietary software (check accreditation for usage on/within DoD computing systems) would be provisioned within the pilot project. Any additional equipment/software/etc. would need to be reviewed by stakeholders to ensure compatibility and feasibility (especially relative to cost) for transfer across other Army installations.

\subsubsection{Stakeholder information}

- Coordination required between: Fort Jackson, DCS G-9 ISE, IMCOM G-9, ASA IE\&E Strategic Integration, and ERDC-CERL.

- Installation: Fort Jackson.

- Contract POC: TBD.

\subsubsection{Business case analysis}

\subsubsection{Cost framework}

- Requirements Analysis includes the kickoff of the project, and costs will be incurred for any required initial hardware/software procurement, onsite system setup, cybersecurity authorization costs, costs for repairs/improvements identified, and annually recurring support/licensing costs. Cost data will also include any potentially ongoing required analytics support or any required reoccurring validation to ensure proper functioning of analytics. 
- Data should be collected to support all capabilities even if the analytics algorithms are not yet completed or phased-into the pilot. This will ensure that follow-on projects or future analytics additions will have a backlog of data to utilize for algorithm development and adequate validation periods (especially important for capturing the child development continuum).

- Period of data collection will be stretched over a 25-month project period, with 3 months before and 4 months after minimum after 18-month data collection period for finalization of system and report writing.

- Solution Development will ensure continued project management, surveillance and analytics validation (for software as well as hardware), continued algorithm development, and monitoring throughout the duration of the projects.

- Project delivery will include (not limited to) system fine-tuning and final validation, finalization of sensor positioning, confirmation of cybersecurity controls, and will ensure that proponent CDC staff is trained on data collection and storage protocols, user interface and relevant controls. Deliverable includes a final project report and onsite presentation to proponent CDC.

\subsubsection{Alternatives}

- Status Quo: Status quo at installations is a VSS that does not include machine learning or Video Analytics. Videos are used for monitoring only and are attended to by humans for checking activity/etc. As there is no Video Analytics system in place, there is currently no enhanced system to assist CDC staff in performing all aspects of CDC functions, so it is all workforce based and reliant on alert and well-trained staff.

- Alternative Courses of Action (COAs): May include phasing in various elements of the pilot program outlined here. Follow-on funding could also be used to assist with funding gaps, as well as further analytics build-out if recommended.

- COA selection: Will be based on competitive procurement and availability of funds for additional funding of contract options.

- Pilot technologies and COAs are expected to support the following :.

- Protecting and Supporting Mission Readiness.

- Support for meeting statutory requirements, National Accreditation, and DoD Certification.

- Support and enhance staff training.

- Support to personnel and community.

- Enhance site safety and security. 


\subsubsection{Risk assessment \& mitigation strategies}

- Technical Risks: Potential cybersecurity risks exist. Also depending on the technical specialty of the contractor (or consortium of contractors) chosen for the pilot project, not all capabilities might be feasibly realized, due to varying Video Analytics skillsets and software packages/analytics algorithms / etc.

- Mitigation Strategy: Ensure Army cybersecurity protocols are followed; try to avoid introducing non-accredited software so that lead time for approvals is avoided (project duration will likely not be able to accommodate waiting time for accreditation/approvals).

- Cost Risks: Costs risks are low given that Smart CDC VSS and Video Analytics pilot program and capability scope can be tailored to fit availability of funds.

- Mitigation Strategy: include contract options that best facilitate tailoring project award to availability of funding (e.g., offering capability options); also realizing that potential follow-on funding could cover some gaps if initial Pilot contract is not able to cover full project options.

- Business or Operational Risks: From a human standpoint, there is the risk that CDC staff could get lazy and rely on the technology instead of the normal surveillance/monitoring/safety protocols and humanpowered checks. It must be clear that this type of surveillance and analytics system will not replace human interaction. This is not a robotized solution. This technology implementation is meant to be able to help, not take the place of CDC personnel functions. There is also always a risk with technology that something will fail. If some part or all of the VSS and Video Analytics system is not functioning properly at any given time, then CDC personnel need to be able to retain full CDC childcare and compliance functions.

- Mitigation Strategy: Ensure that CDC staff are fully trained in hands-on care without relying on automated alerts, video surveillance, and analytics. Ensure periodic checks of functionality in event that VSS and Video Analytics system is non-functional. Include training on the "what-if's" of how to react and carry on if any component of (or all of) the system has failed or is temporarily nonfunctional. Ensure staff become practiced and are always alert and attentive to childcare duties and to VSS and Video Analytics system even while it is fully functional.

- Adversary Risks: There is the risk of networks/components/data not being secure. Prevention of loss of PII, facial recognition data, other 
intrusive breaches (such as but not limited to: hijacking the entry/exit identification process to ensure that children remain with authorized caregivers) are paramount to prevent adversaries from threatening childcare environment, as well as for safety of both the children and Army personnel (parents of all rankings); all this impacts mission readiness if compromised.

- Mitigation Strategy: Must comply with all DoD cybersecurity requirements. Safeguard systems must be in place in event of VSS or Video Analytics failures or outages. In addition, CDC staff must remain vigilant and aware; this system is not meant to replace human monitoring presence.

\subsubsection{Return on investment}

Table 2-2o lists the anticipated quantifiable and non-quantifiable benefits of the pilot technology.

Table 2-20. Smart Child Development Center (CDC) benefits breakdown.

\begin{tabular}{|c|c|}
\hline Anticipated Quantifiable Benefits & Anticipated Non-Quantifiable Benefits \\
\hline $\begin{array}{l}\text { - Ensuring ratios and accountability, as } \\
\text { well as health and safety associated } \\
\text { with medical and SIDS protocols will } \\
\text { ensure basic measures of } \\
\text { compliance, thus retaining licensure, } \\
\text { accreditation, and DoD certification. } \\
\text { If any of these are lost, the entire } \\
\text { CDC must shut down, therefore losing } \\
324 \text { childcare spaces and also losing } \\
\text { childcare for Army personnel. Without } \\
\text { childcare, personnel will not be able } \\
\text { to do their job and train, thus } \\
\text { affecting qualitative elements such } \\
\text { as mission readiness. }\end{array}$ & $\begin{array}{l}\text { - The assurance for Installation/Staff/Parents } \\
\text { that the children are being well cared for is } \\
\text { critical to the comfort levels of Army personnel. } \\
\text { The more comfortable and safer that a parent } \\
\text { feels leaving children in the care of the CDC, the } \\
\text { lower stress levels. This leads to a better ability } \\
\text { to focus on their job, training, and thus has a } \\
\text { positive impact to mission readiness. This also } \\
\text { benefits the children, since they will be happier } \\
\text { and healthier (not to mention, alive). Children } \\
\text { who are supported in a non-stressful } \\
\text { environment will exhibit less behavior issues, } \\
\text { have less developmental delays, and overall be } \\
\text { happier and healthier. These are all benefits } \\
\text { that tie into family welfare, and thus mission } \\
\text { readiness. }\end{array}$ \\
\hline $\begin{array}{l}\text { - Identification of behaviors such as } \\
\text { any harmful or abusive behaviors, as } \\
\text { well as negligence, is critical toward } \\
\text { retaining compliance., thus retaining } \\
\text { licensure, accreditation, and DoD } \\
\text { certification. If any of these are lost, } \\
\text { the entire CDC must shut down, } \\
\text { therefore losing } 324 \text { childcare spaces } \\
\text { and also losing childcare for Army } \\
\text { personnel. Without childcare, } \\
\text { personnel will not be able to do their } \\
\text { job and train, thus affecting } \\
\text { qualitative elements such as mission } \\
\text { readiness. }\end{array}$ & $\begin{array}{l}\text { - Being able to identify developmental } \\
\text { milestones, delays, transition readiness will } \\
\text { assist staff in ensuring appropriate class } \\
\text { assignments which will also provide behavioral } \\
\text { support since children will have their } \\
\text { developmental needs met and be less likely to } \\
\text { act out. Also this capability has the potential to } \\
\text { identify behavioral issues that might stem from } \\
\text { some type of abuse at home (or at the CDC if } \\
\text { the issue is a staff member); child care } \\
\text { providers are key identifiers of domestic child } \\
\text { abuse, and thus these indications could save } \\
\text { lives. }\end{array}$ \\
\hline
\end{tabular}




\begin{tabular}{|c|c|}
\hline Anticipated Quantifiable Benefits & Anticipated Non-Quantifiable Benefits \\
\hline $\begin{array}{l}\text { This provides an appropriate } \\
\text { environment and appropriate } \\
\text { teaching for children, thus ensuring } \\
\text { correct social and emotional support } \\
\text { for children. These elements are } \\
\text { evaluated within DoD certification to } \\
\text { ensure appropriate levels of childcare } \\
\text { provision. If DoD certification is lost, } \\
\text { the entire CDC must shut down, } \\
\text { therefore losing } 324 \text { childcare spaces } \\
\text { and also losing childcare for Army } \\
\text { personnel. Without childcare, } \\
\text { personnel will not be able to do their } \\
\text { job and train, thus affecting } \\
\text { qualitative elements such as mission } \\
\text { readiness. }\end{array}$ & $\begin{array}{l}\text { - This also ensures that there is a monitor on the } \\
\text { quality of care being provided, which affects the } \\
\text { success of both individual children as well as } \\
\text { the classroom groups as a whole. This also } \\
\text { supports early identification of developmental } \\
\text { delays, which ensures that children get the } \\
\text { assistance they might need as early as possible. } \\
\text { This provides support to families, ensuring that } \\
\text { they spend less time struggling with } \\
\text { developmental / behavioral issues, which } \\
\text { alleviates stress and impacts their ability to do } \\
\text { their jobs - thus increasing mission readiness. }\end{array}$ \\
\hline $\begin{array}{l}\text { - Ensuring facility maintenance and } \\
\text { upkeep will ensure basic measures of } \\
\text { compliance, thus retaining licensure, } \\
\text { accreditation, and DoD certification. } \\
\text { If any of these are lost, the entire } \\
\text { CDC must shut down, therefore losing } \\
324 \text { childcare spaces and also losing } \\
\text { childcare for Army personnel. Without } \\
\text { childcare, personnel will not be able } \\
\text { to do their job and train, thus } \\
\text { affecting qualitative elements such } \\
\text { as mission readiness. Some of the } \\
\text { energy tracking elements of this } \\
\text { capability will also contribute to } \\
\text { saved energy, thus also providing a } \\
\text { higher measure of ROI. }\end{array}$ & $\begin{array}{l}\text { - Facility Operations are essential to any } \\
\text { business, especially one regulated as strictly as } \\
\text { a childcare center. By ensuring facility } \\
\text { operations are in working order and safe, the } \\
\text { Installation/Staff/Parents are provided with } \\
\text { safeguards toward maintaining compliance and } \\
\text { the knowledge that the facility their children are } \\
\text { in is safe and well maintained. This in turn } \\
\text { decreases stress levels in staff and parents, } \\
\text { which will then be reflected in the children, } \\
\text { benefitting everyone and maintaining family } \\
\text { welfare and mission readiness. }\end{array}$ \\
\hline
\end{tabular}




\section{Summary}

The Installations of the Future industry day was a success in drawing together a wide cross section of Army installation leadership, industry, and academia. The 10 use cases developed by the Army Secretariat had high numbers of commercial solutions available; engagement with industry helped refine pilot requirements, budgets, schedules, and possible standards for potential enterprise-wide adoption of multiple vendors' solutions in the future. These results are incorporated into demonstration plans and acquisition strategies for each of the use cases to prepare for arrival of Army funding. This effort had the secondary benefit of connecting related stakeholders from across the Army installation community. Army teams continue exploring several use cases to refine and update requirements and identify new commercial solutions they discover. Lastly, other Services' members attended Industry Day due to the similarity of needs and requirements for their installations. Ongoing collaboration with the other Services continues to refine the use case requirements based upon Services' progress on their own pilots. As the Army implements an installations test and demonstration program for commercial technologies, regular interaction between the Army and industry will be valuable to identify opportunities for technology to improve the installations' resilience and operational capabilities. 


\section{Acronyms and Abbreviations}

\begin{tabular}{|c|c|}
\hline Abbreviation & Term \\
\hline ACOM & Army Command \\
\hline ADEP & Area Development Execution Plan \\
\hline ADP & Area Development Plan \\
\hline $\mathrm{Al}$ & Artificial Intelligence \\
\hline AlE & Automated Installation Entry \\
\hline ATO & Authority To Operate \\
\hline BCA & Business Case Analysis \\
\hline BCS & Building Control Systems \\
\hline CAD & Computer-Aided Dispatch \\
\hline CDC & Child Development Center \\
\hline $\mathrm{COA}$ & Course of Action \\
\hline COP & Common Operating Picture \\
\hline COTS & Commercial Off The Shelf \\
\hline CYS & Child and Youth Services \\
\hline $\mathrm{DCl}$ & Defense Critical Infrastructure \\
\hline DoD & Department of Defense \\
\hline DODIN & Department of Defense Information Network \\
\hline ERDC & Engineer Research and Development Center \\
\hline FAC & Facility Analysis Category \\
\hline FCA & Facility Condition Assessment \\
\hline FedRAMP & U.S. Federal Risk and Authorization Management Program \\
\hline FRCS & Facility Related Control Systems \\
\hline GOTS & Government off-the-Shelf \\
\hline $\mathrm{HNC}$ & Huntsville Center, Alabama \\
\hline HQIIS & [Army] Headquarters Installation Information System \\
\hline HVAC & Heating, Ventilating, and Air-Conditioning \\
\hline IEW\&S & Intelligence, Electronic Warfare and Sensors \\
\hline IEWP & Installation Energy and Water Plan \\
\hline IoT & Internet of Things \\
\hline IP & Internet Protocol \\
\hline IPB & Installation Planning Board \\
\hline
\end{tabular}




\begin{tabular}{|c|c|}
\hline Abbreviation & Term \\
\hline IR & Infrared \\
\hline IT & Information Technology \\
\hline LAN & Local Area Network \\
\hline LOE & Line of Effort \\
\hline LPR & License Plate Recognition \\
\hline M\&S & Maintenance and Support \\
\hline$M \& V$ & Measurement and Verification \\
\hline MCX & Huntsville Mandatory Center of Expertise \\
\hline MDO & Multi-Domain Ops \\
\hline MICA & Mobile Information Collection Application \\
\hline MICC & Mission Installation Contracting Command \\
\hline MILCON & Military Construction \\
\hline NIST & National Institute of Standards and Technology \\
\hline O\&M & Operations and Maintenance \\
\hline OT & Operational Technology \\
\hline PEO & Program Executive Officer \\
\hline PII & Personally Identifying Information \\
\hline PPBE & Planning, Programming, Budgeting, and Execution \\
\hline PPBES & Planning, Programming, Budgeting, and Execution System \\
\hline QC & Quality Control \\
\hline ReVAMP & Real-time Virtual Master Planning \\
\hline RFI & Request for Information \\
\hline RFP & Requests for Proposal \\
\hline RIF & Reduction in Force \\
\hline RMF & Risk Management Framework \\
\hline ROI & Return on investment \\
\hline SCG & Security Classification Guide \\
\hline SF & Standard Form \\
\hline SIDS & Sudden Infant Death Syndrome \\
\hline SME & Subject Matter Expert \\
\hline SMS & Sustainment Management System \\
\hline SOW & Statement of Work \\
\hline SRM & Sustainment, Restoration, and Modernization \\
\hline
\end{tabular}




\begin{tabular}{|l|l|}
\hline Abbreviation & Term \\
\hline TBD & To Be Determined \\
\hline TTP & Tactics, Techniques, and Procedures \\
\hline TVA & Tennessee Valley Authority \\
\hline UESC & Utility Energy Service Contract \\
\hline UFC & Unified Facilities Criteria \\
\hline UMCS & Utility Monitoring and Control System \\
\hline USACE & U.S. Army Corps of Engineers \\
\hline VSS & Video Surveillance System \\
\hline VTIME & Virtual Testbed for Installation Mission Effectiveness \\
\hline
\end{tabular}




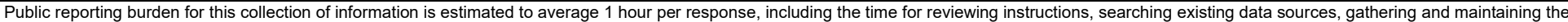

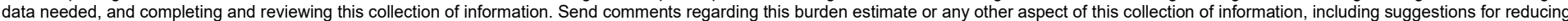

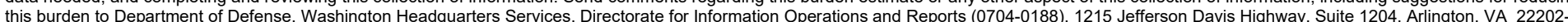

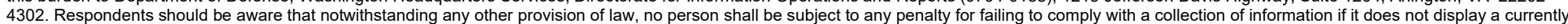
4302. Respondents should be aware that notwithstanding any other provision of law, no person shall
valid OMB control number. PLEASE DO NOT RETURN YOUR FORM TO THE ABOVE ADDRESS.
1. REPORT DATE (DD-MM-YYYY) $10 / 01 / 2020$
Final Technical Report (TR)

\section{TITLE AND SUBTITLE}

Army Installations of the Future Industry Day 2019: Summary Report
3. DATES COVERED (From - To)

5a. CONTRACT NUMBER

5b. GRANT NUMBER

5c. PROGRAM ELEMENT

5d. PROJECT NUMBER

6. AUTHOR(S)

Lance R. Marrano, Anne P. Koster, Susan R. Wolters, Louis B. Bartels, Imes Chu, Brian C. Clark, Tapan C.

Patel, Eileen T. Westervelt, Irene A. Andsager, and Sean M. Wallace

\section{5e. TASK NUMBER}

5f. WORK UNIT NUMBER

8. PERFORMING ORGANIZATION REPORT NUMBER

ERDC TR-20-23

U.S. Army Engineer Research and Development Center (ERDC)

Construction Engineering Research Laboratory (CERL)

PO Box 9005,

Champaign, IL 61826-9005

\section{SPONSORING / MONITORING AGENCY NAME(S) AND ADDRESS(ES)}

Office of the Assistant Secretary of the Army, Installations, Energy and Environment OASA(IE\&E)

110 Army Pentagon, Room 3E464

Washington, DC 20310-0110

\section{DISTRIBUTION / AVAILABILITY STATEMENT}

Approved for public release; distribution is unlimited.

\section{SUPPLEMENTARY NOTES}

This work was funded via reimbursable Funding Authorization Document (FAD) 11256903m, "WI A1140-FY19 Industry Day."

\section{ABSTRACT}

The Army Installations of the Future Industry Day was held on 23 May 2019 at the Renaissance Capital View hotel in Arlington, VA to identify the availability and maturity of specific commercial off-the-shelf (COTS) "smart installation" capabilities, technologies, and products; and to seek interest from industry in exploring potential approaches, requirements, standards, and/or specifications for pilot demonstrations at Army installations focused on 10 use-case technology areas. The Industry Day event included approximately 336 participants comprised of Academia (5), Industry (226), and Government (105). This report presents "road maps" that outline the Army's desired outcomes for the target technology areas and potential pilot technology demonstrations.

\section{SUBJECT TERMS}

Military bases, Technology-Evaluation, Trade shows

\section{SECURITY CLASSIFICATION OF:}

a. REPORT
Unclassified

NSN 7540-01-280-5500

\section{b. ABSTRACT \\ Unclassified}

\section{c. THIS PAGE}

Unclassified

17. LIMITATION
OF ABSTRACT
SAR

18. NUMBER OF PAGES

95 19a. NAME OF RESPONSIBLE PERSON

19b. TELEPHONE NUMBER (include area code) 